\title{
Neuregulin-1 elicits a regulatory immune response following traumatic spinal cord injury
}

\author{
Arsalan Alizadeh", Kallivalappil T. Santhosh', Hardeep Kataria', Abdelilah S. Gounni ${ }^{2}$ \\ and Soheila Karimi-Abdolrezaee ${ }^{1^{*}}$
}

\begin{abstract}
Background: Spinal cord injury (SCl) triggers a robust neuroinflammatory response that governs secondary injury mechanisms with both degenerative and pro-regenerative effects. Identifying new immunomodulatory therapies to promote the supportive aspect of immune response is critically needed for the treatment of SCl. We previously demonstrated that $\mathrm{SCl}$ results in acute and permanent depletion of the neuronally derived Neuregulin-1 (Nrg-1) in the spinal cord. Increasing the dysregulated level of Nrg-1 through acute intrathecal Nrg-1 treatment enhanced endogenous cell replacement and promoted white matter preservation and functional recovery in rat SCl. Moreover, we identified a neuroprotective role for $\mathrm{Nrg}-1$ in moderating the activity of resident astrocytes and microglia following injury. To date, the impact of $\mathrm{Nrg}^{-1}$ on immune response in $\mathrm{SCl}$ has not yet been investigated. In this study, we elucidated the effect of systemic Nrg-1 therapy on the recruitment and function of macrophages, T cells, and B cells, three major leukocyte populations involved in neuroinflammatory processes following $\mathrm{SCl}$.
\end{abstract}

Methods: We utilized a clinically relevant model of moderately severe compressive SCI in female Sprague-Dawley rats. Nrg-1 (2 $\mu \mathrm{g} /$ day) or saline was delivered subcutaneously through osmotic mini-pumps starting $30 \mathrm{~min}$ after SCl. We conducted flow cytometry, quantitative real-time PCR, and immunohistochemistry at acute, subacute, and chronic stages of SCl to investigate the effects of Nrg-1 treatment on systemic and spinal cord immune response as well as cytokine, chemokine, and antibody production.

Results: We provide novel evidence that Nrg-1 promotes a pro-regenerative immune response after SCl. Bioavailability of Nrg-1 stimulated a regulatory phenotype in T and B cells and augmented the population of $\mathrm{M} 2$ macrophages in the spinal cord and blood during the acute and chronic stages of SCl. Importantly, Nrg-1 fostered a more balanced microenvironment in the injured spinal cord by attenuating antibody deposition and expression of pro-inflammatory cytokines and chemokines while upregulating pro-regenerative mediators.

Conclusion: We provide the first evidence of a significant regulatory role for $\mathrm{Nrg}-1$ in neuroinflammation after SCl. Importantly, the present study establishes the promise of systemic Nrg-1 treatment as a candidate immunotherapy for traumatic SCl and other CNS neuroinflammatory conditions.

Keywords: Spinal cord injury, Neuregulin-1, Neuroinflammation, T cells, B cells, Macrophages, Autoantibodies, Cytokines and chemokines, Rat

\footnotetext{
* Correspondence: Soheila.Karimi@umanitoba.ca

${ }^{1}$ Regenerative Medicine Program, Department of Physiology and

Pathophysiology, Faculty of Medicine, Spinal Cord Research Centre,

University of Manitoba, 629-Basic Medical Sciences Building, 745 Bannatyne

Avenue, Winnipeg, Manitoba R3E 0J9, Canada

Full list of author information is available at the end of the article
}

(c) The Author(s). 2018 Open Access This article is distributed under the terms of the Creative Commons Attribution 4.0 International License (http://creativecommons.org/licenses/by/4.0/), which permits unrestricted use, distribution, and reproduction in any medium, provided you give appropriate credit to the original author(s) and the source, provide a link to the Creative Commons license, and indicate if changes were made. The Creative Commons Public Domain Dedication waiver (http://creativecommons.org/publicdomain/zero/1.0/) applies to the data made available in this article, unless otherwise stated. 


\section{Background}

Pathophysiology of spinal cord injury (SCI) is characterized by a robust humoral and cellular neuroinflammatory response that is driven by the interplay between the peripherally recruited leukocytes and resident glial cells $[1,2]$. Microglia/macrophages, T cells, and B cells play central roles in orchestrating the innate and adaptive immune responses following SCI through a plethora of inflammatory cytokines, chemokines, antibodies, and proteolytic enzymes [2-4]. Activated microglia/macrophages mediate the initial neuronal injury through proinflammatory mediators and oxidative damage [5]. They also activate $\mathrm{T}$ cells through their antigen presenting function [1]. Activated T cells stimulate B cells, through a host of cytokines and signaling molecules, to produce autoreactive antibodies against spinal cord tissue [6] causing tissue damage through antibody-mediated cytotoxicity $[7,8]$. These processes collectively lead to an imbalanced and dysregulated milieu that impedes repair and regeneration after SCI [1]. Despite their undisputed role in degenerative processes following SCI, emerging evidence indicates that immune cells can be modulated in their microenvironment to adopt regulatory and proregenerative phenotypes $[9,10]$. Given the profound impact of neuroinflammation on SCI pathophysiology, it is critical to unravel endogenous mechanisms that regulate immune cells after injury. This knowledge is vital for developing immunotherapies that can harness the potential of immune cells in fostering a supportive microenvironment for spinal cord repair and regeneration.

We previously identified that SCI results in a rapid and long-lasting decline in the tissue levels of the neuronally derived growth factor, Neuregulin-1 (Nrg-1) [11]. $\mathrm{Nrg}-1$ is primarily known for its essential role in Schwann cell and oligodendrocyte differentiation, maintenance, and myelination in the central and peripheral nervous systems [12]. In a preclinical model of compressive/contusive SCI in rats, we demonstrated that increasing the deficient bioavailability of $\mathrm{Nrg}-1$ in the injured spinal cord improves neurological recovery following injury [13]. In our efforts to elucidate the mechanisms underpinning the recovery of function after Nrg-1 treatment [13], we identified that Nrg-1 promotes oligodendrogenesis and protects oligodendrocytes and axons resulting in white matter preservation after SCI [11]. Importantly, we found a remarkable positive role for Nrg-1 in regulating astrogliosis and glial scar formation in the injured spinal cord [13]. Moreover, Nrg-1 treatment through intrathecal infusion attenuated the release of pro-inflammatory cytokines, tumor necrosis factor-alpha (TNF- ), and interleukin-1 beta (IL-1 $\beta$ ) in acute SCI while increasing the tissue levels of the antiinflammatory cytokine, IL-10 at subacute SCI [13]. Other studies have also shown a neuroprotective role for
Nrg-1 in attenuating neuronal injury in vitro and in ischemic brain injury models by reducing neurotoxicity and pro-inflammatory mediators $[14,15]$. These initial findings suggest a potential immunomodulatory mechanism of Nrg-1 in fostering a pro-regenerative microenvironment that improves tissue preservation and neurological recovery following SCI [13].

In the present study, we dissected the impact of Nrg-1 on the peripheral and spinal cord immune responses at various stages of SCI. Using a clinically relevant model of severe compressive SCI in rat, we investigated whether systemic delivery of recombinant human Nrg-1 (rhNrg-1) could regulate the recruitment, phenotype, and secretory properties of SCI relevant leukocytes in the blood and injured spinal cord. We demonstrate, for the first time, that Nrg-1 promotes a comprehensive immune regulatory response by macrophages and $\mathrm{T}$ and $\mathrm{B}$ lymphocytes at acute and chronic stages of SCI through modulation of a repertoire of cytokines and chemokines in the spinal cord tissue. Our new findings establish that bioavailability of Nrg-1 activates a neuroinflammatory process that provides a supportive environment for endogenous repair and recovery of function following SCI.

\section{Methods}

\section{Rat model of compressive spinal cord injury and animal} care

All animal experiments were approved by the University of Manitoba Animal Care Committee in agreement with the Canadian Council on Animal Care guidelines and policies. A total of 120 age and weight matched (8-10 weeks, 250 g) adult female Sprague-Dawley (SD) rats (Central Animal Care Facility at the University of Manitoba) were used in this study. For SCI surgeries, animals underwent laminectomy at thoracic levels T6-T8 under deep isoflurane anesthesia. To induce compressive SCI, a 35-g aneurysm clip (University Health Network, Toronto, Ontario) was applied for $1 \mathrm{~min}$ at mid-thoracic (T7) level. Each animal received a mixture of buprenorphine (Temgesic ${ }^{\circ}, 0.05 \mathrm{mg} / \mathrm{kg}$ ) and meloxicam (Metacam ${ }^{\circ}$, Boehringer Ingelheim $\mathrm{GmbH}, 2 \mathrm{mg} / \mathrm{kg}$ ) supplemented by three additional doses of buprenorphine every $8 \mathrm{~h}$ for pain management. Rats were housed in a 12:12 h light/dark cycle in standard plastic cages before SCI and afterwards in cages covered with soft paper bedding to prevent skin erosions and urine scalding. Pelleted food and drinking water were available ad libitum. Animals received daily examination with their bladders expressed three times a day until regaining full reflexive bladder control.

\section{Experimental groups and treatments}

Prior to surgeries, animals were randomly divided into three experimental groups: (1) uninjured control; (2) 
$\mathrm{SCI} /$ vehicle control, which received vehicle solution used for rhNrg- $1 \beta 1$ delivery $(0.1 \%$ bovine serum albumin, BSA, in $0.9 \%$ saline); and (3) SCI/Nrg-1, which received rhNrg-1 $11,2 \mu \mathrm{g} /$ day systemically using subcutaneously implanted osmotic mini-pumps (Alzet ${ }^{\circ}$ model \#1003D for 3 days, model \#2001 for 7 days, model \#2002 for 14 days, and model \#2006 for 42 days). The dosage of rhNrg-1 $\beta 1$ (Shenandoah Biotechnology Inc., Cat \# 10046-50) was determined based on our previous study [13] where we found significant structural and functional recovery with a dose range of 0.5 to $1.5 \mu \mathrm{g}$ per day of rhNrg- $1 \beta 1$ delivered intrathecally into the subarachnoid space. In this study, we delivered Nrg-1 systemically, thus the dose was increased to $2 \mu \mathrm{g} /$ day to ensure adequate delivery of Nrg-1 to the spinal cord. Treatment was started approximately $30 \mathrm{~min}$ after SCI.

\section{Flow cytometric assessment of spinal cord immune cells}

At each end point, animals were deeply anesthetized using a mixture of $40 \%$ isoflurane $+60 \%$ propylene glycol. Then, animals were sacrificed, and spinal columns were excised and placed on dry ice for $5 \mathrm{~min}$. The spinal cords were then exposed using laminectomy, and $1.5 \mathrm{~cm}$ of tissue centering the epicenter of the injury was excised. Mechanical dissociation was performed in Hank's Balanced Salt Solution (HBSS) using fine scissors, and the tissue was retrieved by centrifugation at $1000 \mathrm{rpm}$ for $1 \mathrm{~min}$ at room temperature. Tissue particles were then enzymatically dissociated by incubating with $2.5 \mathrm{mg}$ trypsin $+5 \mathrm{mg}$ collagenase in $5 \mathrm{ml}$ Dulbecco's modified Eagle's media (DMEM, $20 \mathrm{~min}$, at $37{ }^{\circ} \mathrm{C}$ ). Following trituration, the enzymatic reaction was stopped using $10 \mathrm{ml}$ DMEM + 10\% fetal bovine serum (FBS) and tissue mixture was filtered through a $40-\mu \mathrm{m}$ cell strainer. Cells were pelleted and reconstituted in $6 \mathrm{ml}$ of HBSS and overlaid on OptiPrep (Sigma-Aldrich, D1556) gradient and centrifuged at $1900 \mathrm{rpm}$ for $15 \mathrm{~min}$ at $20{ }^{\circ} \mathrm{C}$ for separation of myelin debris from immune cells [16]. Supernatant, containing myelin and tissue debris, was carefully discarded, and cells were washed and re-suspended in $2.5 \mathrm{ml}$ of HBSS. Cells were then incubated with RBC lysis buffer (Biolegend, 420301), washed, and counted. A total of 7.5 million cells were harvested from each animal. For each antibody panel, 2 million cells per animal were used. Non-specific binding sites were blocked using $10 \%$ normal mouse serum for 30 min (Invitrogen, 10410). Cells were then incubated with antibody cocktail containing surface antibodies for each panel (listed in Table 1) for $30 \mathrm{~min}$ in dark at $4{ }^{\circ} \mathrm{C}$. Cells were then fixed using BD ${ }^{\mathrm{mm}}$ Cytofix Fixation Buffer for 15 min at $4{ }^{\circ} \mathrm{C}(\mathrm{BD}, 554655)$.

For intracellular (cytokine) staining, following fixation, cells were incubated with permeabilizing buffer $(0.1 \%$ saponin + 10\% FBS in HBSS) for $30 \mathrm{~min}$ and incubated with a cocktail of intracellular antibodies for $30 \mathrm{~min}$ in dark. For FoxP3 staining, after surface antibody staining and before fixation, cells were incubated with FoxP3 fix/ perm buffer for 20 min and washed in FoxP3 perm buffer (FoxP3 fix/perm buffer set, Biolegend, 421403). Cells were then incubated with perm buffer for $15 \mathrm{~min}$ and incubated with a cocktail of FoxP3 and IL-10 antibodies for $30 \mathrm{~min}$. Finally, cells were washed with flow cytometry staining buffer (10\% FBS in PBS) and reconstituted with $500 \mu \mathrm{l}$ of this buffer and analyzed using BD FACS Canto II flow cytometer counting 200,000 events per sample. Compensation was done using single-stained beads (OneComp eBeads, 501129031, eBioscience). For each antibody panel, specific isotype controls were used to account for non-specific antibody binding (flow cytometry antibodies and their isotype controls are listed in Table 1. Gating strategies for macrophages, $\mathrm{T}$ cells, and B cells are shown in Figs. 1, 2, 3, and 4. Verification of antibody specificity is shown in Additional file 1 : Figures S1-S3).

\section{Flow cytometric assessment of blood leukocytes}

Upon anesthesia (described above) and before excising spinal cords, $1 \mathrm{ml}$ of blood was collected through a cardiac puncture in syringes coated with and containing $0.5 \mathrm{ml}$ of $100 \mathrm{mM}$ EDTA. Each $200 \mu \mathrm{l}$ of whole blood was mixed with $2 \mathrm{ml}$ of RBC lysis buffer and incubated for $5 \mathrm{~min}$ at room temperature (420301, Biolegend). Cells were centrifuged at $600 \mathrm{~g}$ for $10 \mathrm{~min}$ at $4{ }^{\circ} \mathrm{C}$, and the supernatant containing lysed RBCs was discarded. This procedure was repeated one or two more times until all RBCs were lysed and a clean pellet was obtained. Cells from each animal were then pooled together, washed twice in PBS, and re-suspended in MACS buffer (PBS + $2 \mathrm{mM}$ EDTA $+0.5 \% \mathrm{BSA}, \mathrm{PH}=7.2-7.4)$. Leukocytes were then counted and underwent staining and flow cytometry procedures as described above.

\section{Tissue processing for histological studies}

At each time-point, animals were deeply anesthetized (as described earlier) and were perfused transcardially with $2.5 \%$ paraformaldehyde (PFA) in $0.1 \mathrm{M}$ phosphate buffered saline (PBS). Then, the spinal tissues were postfixed in $2.5 \%$ PFA and 10\% sucrose in PBS overnight. Cryoprotection continued by incubation of tissues in $20 \%$ sucrose in PBS for 2 days. A 2-cm length of the spinal cord centered at the injury epicenter was excised and embedded (Tissue-Tek ${ }^{\circ}$ O.C.T., Electron Microscopy Sciences). Serial cross sections (35 $\mu \mathrm{m}$ thickness) were cut by a cryostat (Leica Biosystems $\mathrm{GmbH}$ ), mounted and cover-slipped on Superfrost ${ }^{\circ}$ Plus Micro Slides (Fischer Scientific), and stored at $-80{ }^{\circ} \mathrm{C}$ until immunostaining procedure. 
Table 1 List of antibodies used for flow cytometric and immunohistochemical assessment of immune cells

\begin{tabular}{|c|c|c|c|c|}
\hline Antibody & Color & Application & Cat number & Concentration \\
\hline $\mathrm{CD3}$ & PerCP & Flow & eBioscience, 46-00-30-82 & $1: 20$ \\
\hline CD4 & BV510 & Flow, IHC & BD, 740138 & 1:20, (1:100 for $\mathrm{IHC})$ \\
\hline Ms lgG2a, k & BV510 & Flow & BD, 563027 & $1: 20$ \\
\hline CD45 & APC-Cy7 & Flow & BD, 561586 & $1: 20$ \\
\hline Ms lgG1, k & APC-Cy7 & Flow & BD, 557873 & $1: 20$ \\
\hline IFN- $\gamma$ & FITC & Flow & BD, 559498 & $1: 20$ \\
\hline Ms lgG1, k & FITC & Flow & $B D, 554679$ & $1: 20$ \\
\hline $\mid \mathrm{L}-10$ & PE & Flow & BD, 555088 & $1: 20$ \\
\hline Ms lgG2b, k & PE & Flow & BD, 555058 & $1: 20$ \\
\hline FoxP3 & APC & Flow, IHC & eBioscience, 17-5773-80 & 1:20, (1:100 for IHC) \\
\hline Ms lgG2a, k & APC & Flow & eBioscience, 17-4724-42 & $1: 20$ \\
\hline CD68 & FITC & Flow, IHC & Bio-Rad, MCA341F & 1:20, (1:100 for $I H C)$ \\
\hline Ms $\lg G 1$ & FITC & Flow & Bio-Rad, MCA1209F & $1: 20$ \\
\hline CD163 & PE & Flow, IHC & Bio-Rad, MCA342R & 1:20, (1:100 for $I H C)$ \\
\hline Ms $\lg G 1$ & PE & Flow & Bio-Rad, MCA1209PE & $1: 20$ \\
\hline CD86 & BV-421 & Flow, IHC & $\mathrm{BD}, 743,211$ & 1:20, (1:100 for $\mathrm{IHC})$ \\
\hline Ms $\lg G 1, k$ & BV-421 & Flow & BD, 562438 & $1: 20$ \\
\hline IL-10 & Alexa 647 & Flow & BD, 562156 & $1: 20$ \\
\hline Ms lgG2b, k & Alexa 647 & Flow & BD, 557903 & $1: 20$ \\
\hline CD45RA & APC-Cy7 & Flow & BD, 561624 & $1: 20$ \\
\hline $\begin{array}{l}\text { Armenian hamster } \\
\text { lgG isotype control }\end{array}$ & PE-Cy7 & Flow & eBioscience, 25-4888-82 & $1: 20$ \\
\hline Anti lba-1, rabbit & Unconjugated & $\mathrm{IHC}$ & Wako, 019-19741 & $1: 500$ \\
\hline Anti CD3, rabbit & Unconjugated & $\mathrm{IHC}$ & Abcam, GR2952321 & $1: 300$ \\
\hline Anti IL-10, mouse & Unconjugated & $\mathrm{IHC}$ & R\&D, MAB519 & $1: 300$ \\
\hline $\begin{array}{l}\text { Goat anti-rabbit } \\
\text { secondary } A b\end{array}$ & Alexa Fluor 647 & $\mathrm{IHC}$ & Invitrogen, A21245 & $1: 400$ \\
\hline $\begin{array}{l}\text { Goat anti-mouse } \\
\text { secondary } \mathrm{Ab}\end{array}$ & Alexa Fluor 568 & $\mathrm{IHC}$ & Invitrogen, A11031 & $1: 400$ \\
\hline
\end{tabular}

Immunohistochemical detection of macrophages and lymphocytes in the injured spinal cord

We utilized the same flow cytometry antibodies for immunohistochemical staining of T cells, B cells, and macrophages. Three tissue sections around $2 \mathrm{~mm}$ rostral or caudal to the epicenter were selected. Sections were washed twice with TBST $(50 \mathrm{mM}$ Tris, $150 \mathrm{mM} \mathrm{NaCl}$, $0.05 \%$ Tween 20, $\mathrm{PH} 7.6$ ) for $15 \mathrm{~min}$ at room temperature. Sections were blocked using 5\% normal mouse serum in TBST for $1 \mathrm{~h}$ at room temperature and incubated with antibodies against cell surface markers for B cells (CD45RA), T cells (CD3), and macrophages (Iba-1, CD68, CD86, CD163),1:500 for Iba-1 and 1:100 for the rest of the antibodies overnight at $4{ }^{\circ} \mathrm{C}$. Sections were then washed twice with TBST and incubated with their corresponding intracellular (IL-10 for B cells, IL-10, and FoxP3 for T cells) antibodies. FoxP3 antibody was diluted in an antibody solution containing 1\% BSA,
$0.1 \%$ cold water fish skin gelatin, $0.5 \%$ Triton $\mathrm{X}-100$, and $0.05 \%$ sodium azide in TBS. Images were taken at $\times 20$ and $\times 63$ using Axio Imager M2 fluorescent microscope (Zeiss) and were processed using ZEN software (Zeiss).

\section{Immunohistochemical assessment of IgG and IgM in the injured spinal cord}

Seven serial cross-sections spanning 7-mm length of the injured spinal cord centered at the injury epicenter were selected with 1-mm interval. Sections were blocked for $1 \mathrm{~h}$ with $5 \%$ mouse serum $+1 \% \mathrm{BSA}+0.3 \%$ Triton $\mathrm{X}-100$ in PBS at room temperature and then incubated with a mixture of anti-IgG (Invitrogen, \#31470, 1:100) and anti-IgM (eBioscience, 14-0990-82, 1:100) antibodies overnight at $4{ }^{\circ} \mathrm{C}$. Sections were then washed three times with PBS and incubated with a mixture of Alexa Fluor ${ }^{\circ}$ 568 donkey anti-goat (A1105, Invitrogen, 1:400) and Alexa Fluor 647 goat anti-mouse (A21236, Invitrogen, 

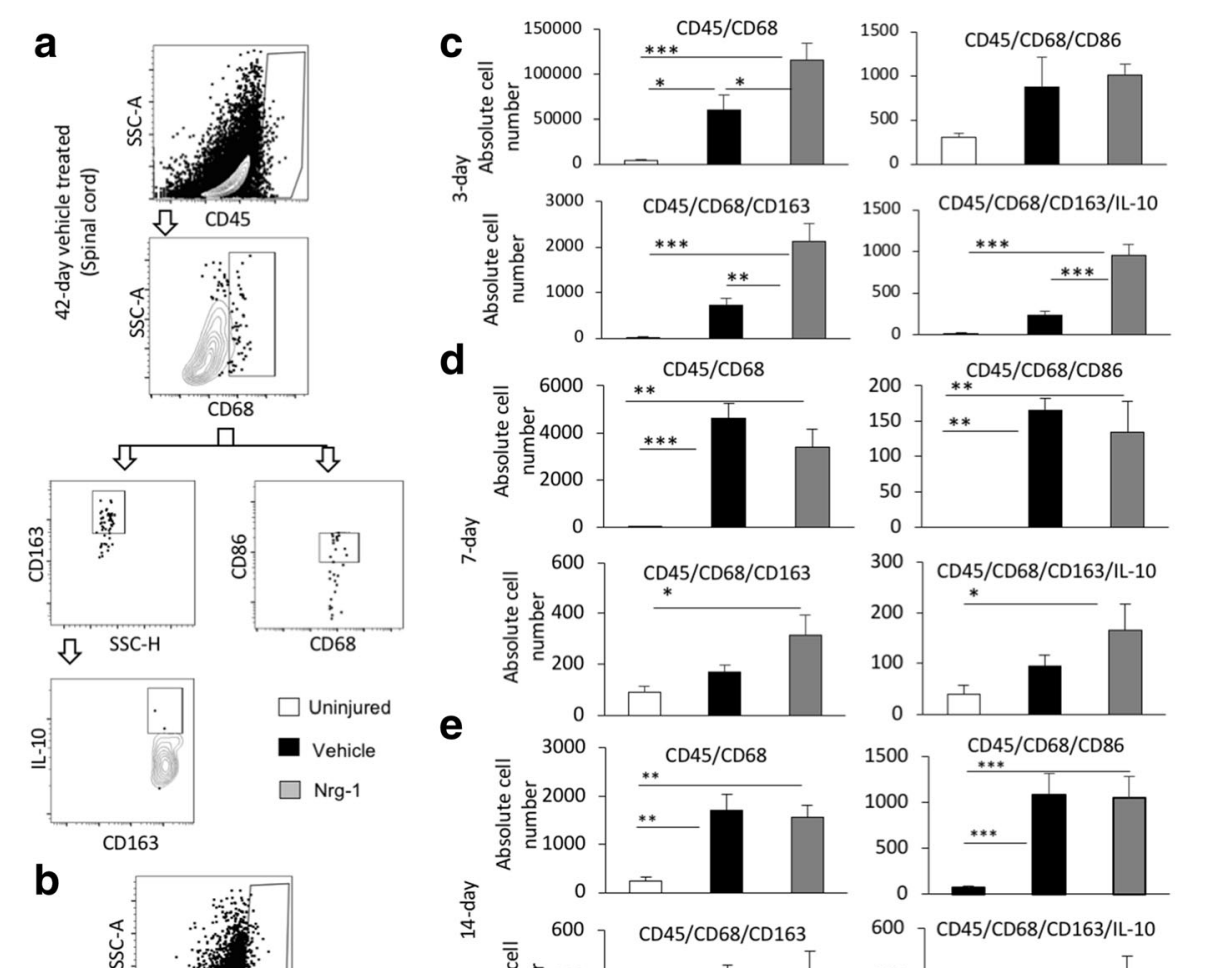

e

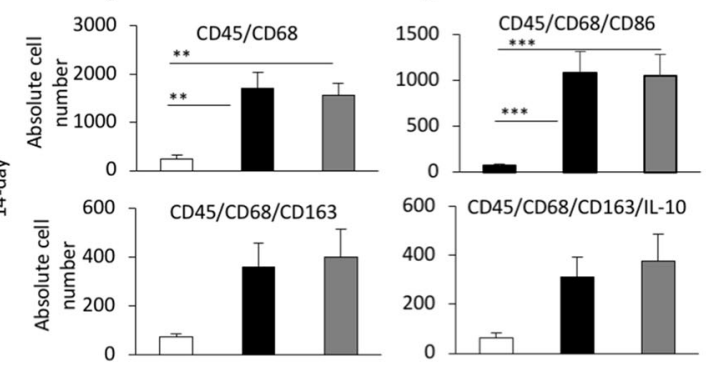

f
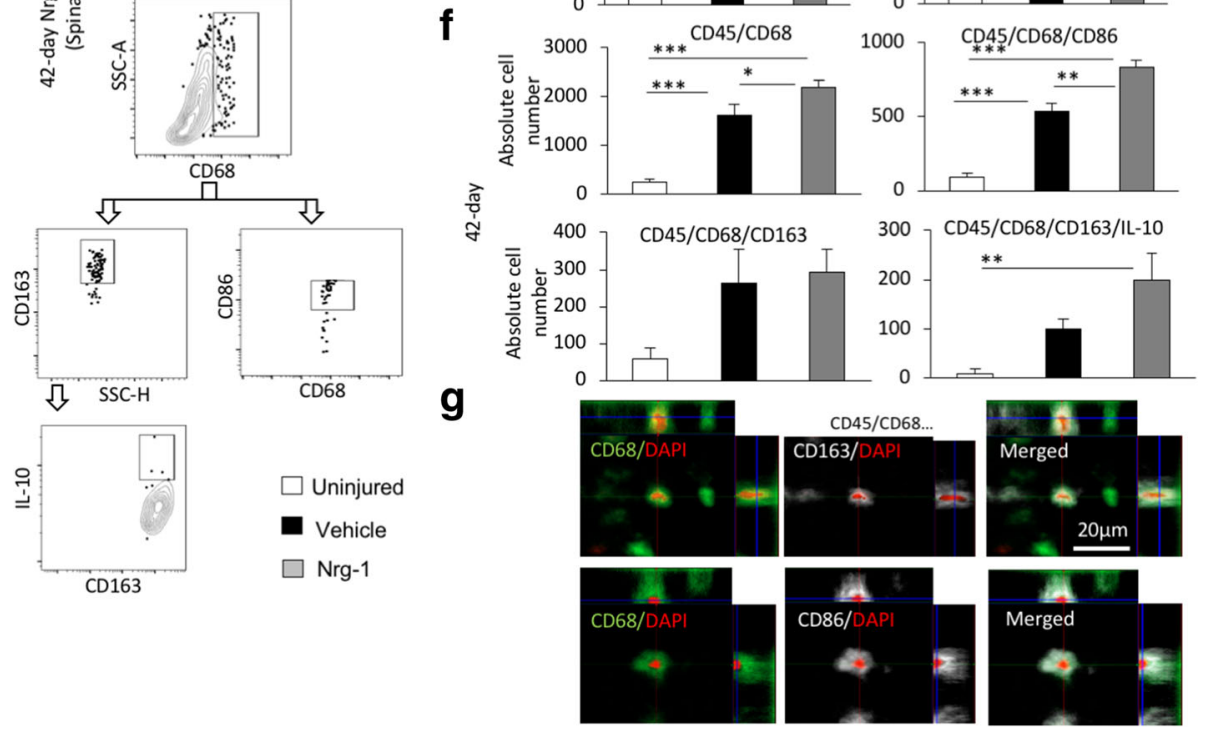

Fig. 1 (See legend on next page.) 


\begin{abstract}
(See figure on previous page.)
Fig. 1 Nrg-1 treatment alters M1 and M2 macrophage populations after SCl. a, b Representative images of the gating strategy for flow cytometry are provided for infiltrated spinal cord macrophages at 42-day post-injury under each treatment group. c Flow cytometric analysis 3 days post-SCI showed a robust increase in the number of macrophages $\left(\mathrm{CD} 45^{+} \mathrm{CD} 68^{+}\right)$in the injured spinal cord. Nrg-1-treated animals demonstrated a significantly higher number of macrophages compared to the vehicle-treated group. Phenotypical analysis of macrophages at 3-day time-point showed no significant difference in the number of infiltrated $\mathrm{M} 1$ macrophages $\left(\mathrm{CD} 45^{+} \mathrm{CD} 68^{+} \mathrm{CD} 86^{+}\right)$between vehicle- and Nrg-1-treated groups. However, Nrg-1-treated SCl animals had a significantly higher population of $\mathrm{M} 2$ macrophages $\left(\mathrm{CD} 45^{+} \mathrm{CD} 68^{+} \mathrm{CD} 163^{+}\right.$and $\left.\mathrm{CD} 45^{+} \mathrm{CD} 68^{+} \mathrm{CD} 163^{+} \mathrm{IL}-10^{+}\right)$in the spinal cord. $\mathbf{d}$, e At 7 and 14 days post$\mathrm{SCl}$, the total number of tissue macrophages and their M1 subpopulation was significantly higher in the injured animals compared to the uninjured group, while M2 macrophage population remained unaltered. There was also no significant difference in the total number of macrophages and their M1 or M2 phenotype between the vehicle- and Nrg-1-treated groups. $\mathbf{f}$ At 42 days post-SCl, the number of infiltrated macrophages was 30 times less than the acute 3-day time-point in SCI baseline condition but still significantly higher than uninjured animals. Compared to both vehicle and uninjured rats, Nrg-1-treated animals showed a significantly higher number of $\mathrm{M} 1$ macrophages. There was no significant difference in the number of $\mathrm{M} 2$ macrophages between the vehicle and Nrg-1 treatment groups at this time-point, although Nrg-1-treated rats had a significantly higher number of M2 macrophages as compared to uninjured animals. $\mathbf{g}$ Immunohistochemical analysis verified the presence of $\mathrm{M} 1\left(\mathrm{CD} 68^{+} \mathrm{CD} 86^{+}\right)$and $\mathrm{M} 2\left(\mathrm{CD} 68^{+} \mathrm{CD} 163^{+}\right)$macrophages in the perilesional area ( $N=5 /$ group/time-point, ${ }^{*} p<0.05,{ }^{* *} p<0.01$, ${ }^{* * *} p<0.001$, one-way ANOVA followed by Holm-Sidak post hoc test)
\end{abstract}

1:400) secondary antibodies for $1 \mathrm{~h}$ at room temperature. Slides were then washed with PBS three times and cover-slipped with Mowiol (Sigma) mounting medium. To avoid variability in our immunohistochemical studies, all samples were processed at the same time under the same conditions. Images were taken at $\times 10$ magnification from whole spinal cord section using AxioImager M2 fluorescence microscope (Zeiss) under consistent exposure time as described previously [11, 17]. Fluorescence intensity was measured using ImageJ analysis software (imagej.nih.gov). After subtracting the background automatically, the immunointensity above the threshold was measured for the entire spinal cord section excluding the cavities and dura matter. To eliminate the differences in the total size of the sections, the following formula was used: normalized immunointensity of tissue section $=$ total immunointensity of tissue section $\mathrm{x} /$ total area of tissue section $\mathrm{x}$.

\section{RNA extraction and quantitative real-time PCR}

At end points, the spinal cords were dissected in icecold artificial cerebrospinal fluid (aCSF, containing $124 \mathrm{mM} \mathrm{NaCl}, 3 \mathrm{mM} \mathrm{KCl}, 1 \mathrm{mM}$ NaHPO4, $26 \mathrm{mM}$ NaHCO3, $1.5 \mathrm{mM} \mathrm{MgSO} 4,1.5 \mathrm{mM} \mathrm{CaCl}$, and $10 \mathrm{mM}$ glucose). Five millimeters of the spinal cord centering the injury epicenter was excised and homogenized in TRIzol reagent (Invitrogen ${ }^{\circ}$ ). RNA was extracted using an RNeasy plus mini kit (Qiagen ${ }^{\odot}$ ) and the first-strand cDNA was synthesized with 5X All-In-One RT MasterMix $\left(\mathrm{ABM}^{\circ}\right)$. Real-time $\mathrm{qPCR}$ reactions were conducted with the PowerUp ${ }^{\text {тm }} \mathrm{CYBR}^{\oplus}$ Green Master Mix (Applied Biosystems $^{\odot}$ ) in an ABI7500 fast thermocycler (Applied Biosystems) as we described before [11]. Primer information is provided in Table 2 .

\section{Statistical analysis}

All statistical analyses were performed using SigmaStat Software. For distance analysis in immunohistological assessments, we used two-way analysis of variance
(ANOVA) followed by Holm-Sidak post hoc test. Oneway ANOVA followed by Holm-Sidak post hoc was used in all flow cytometry and real-time qPCR analyses. The data was reported as a mean \pm standard error of the mean (SEM), and $p \leq 0.05$ was considered as statistically significant. Proper randomization and blinding were employed in all assessments.

\section{Results}

\section{Systemic administration of neuregulin-1 alters the population of $\mathrm{M} 1$ and $\mathrm{M} 2$ macrophages following $\mathrm{SCl}$} Monocyte-derived macrophages play a central role in the inflammatory response following SCI and contribute to both secondary injury mechanisms and repair processes owing to their phenotypic diversity [18]. We previously demonstrated that intrathecal infusion of Nrg-1 reduces the tissue level of pro-inflammatory cytokines in rat compressive SCI while increases IL-10 levels [13]. Here, we delivered Nrg-1 systemically and investigated the recruitment and phenotype of monocyte-derived macrophages in the injured spinal cord. Our flow cytometric assessment of uninjured spinal cord tissue showed minimal or undetectable number of macrophages $\left(\mathrm{CD} 45^{+} \mathrm{CD} 68^{+}\right)$. Our SCI temporal analysis at 3, 7, 14, and 42 days post-injury, representing acute, subacute, and chronic stages of injury, showed infiltration of $\mathrm{CD} 45^{+} \mathrm{CD} 68^{+}$macrophages to the lesion as expected. We found a significant 13.6- and 184-fold increase in the $\mathrm{CD} 45^{+} \mathrm{CD} 68^{+}$cell population at 3 and 7 days postinjury, respectively (Fig. 1c). While remained significantly higher than uninjured control animals, the number of macrophages was decreased to a lower level at 14 days post-injury and onwards up to 42 days, the latest examined time-point (Fig. 1c-f). Nrg-1 treatment significantly increased the population of infiltrated macrophages at 3 days post-injury (1.9-folds) with no significant effect on their population at 7 and 14-day time-points. However, chronically at 42 days post-SCI, Nrg-1 treatment led to a significantly higher number of 


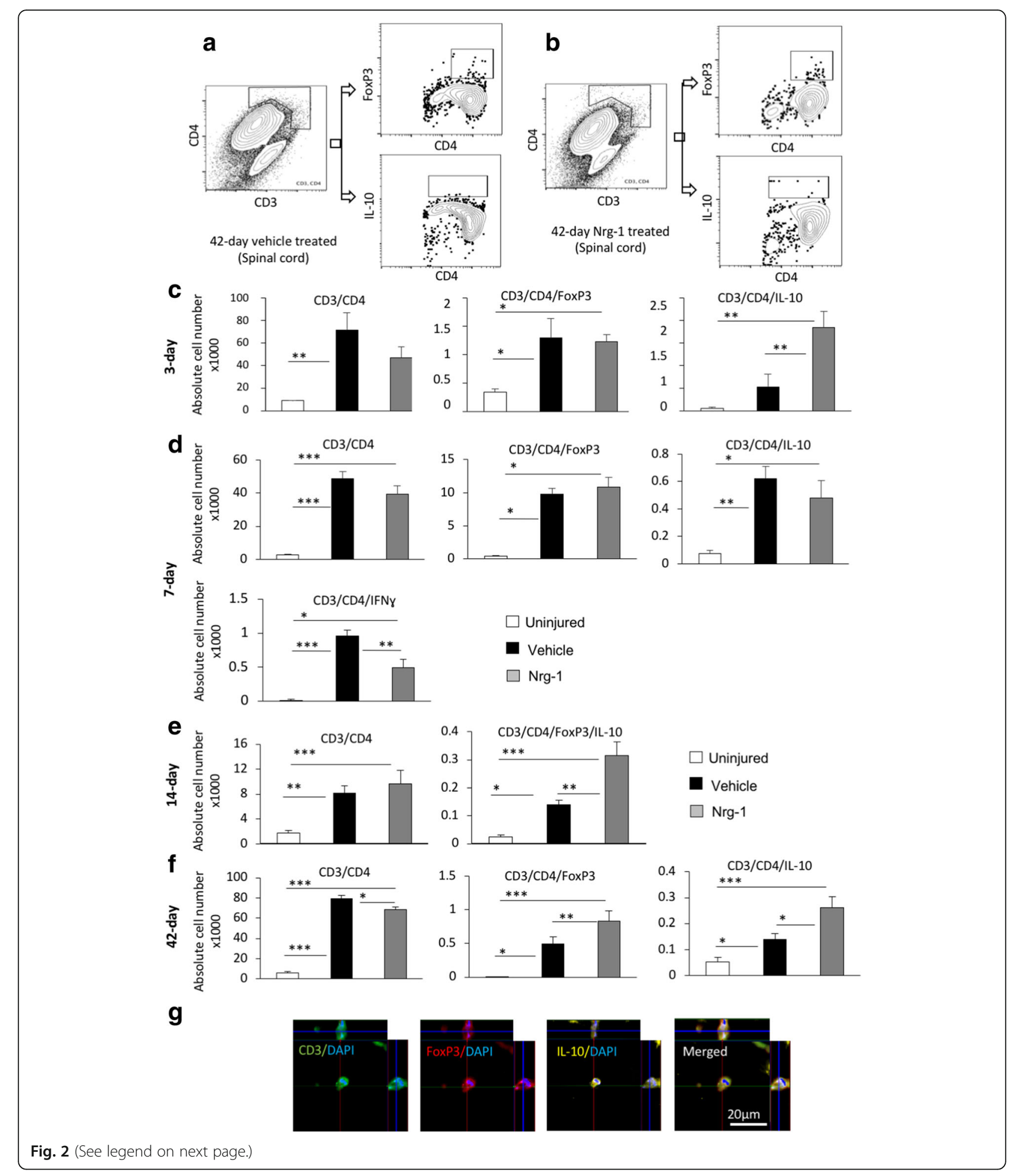


(See figure on previous page.)

Fig. 2 Nrg-1 promotes $T_{\text {reg }}$ cell response in the injured spinal cord. $\mathbf{a}$, $\mathbf{b}$ Representative images of the gating strategy for flow cytometry after singlet selection are provided for vehicle- and Nrg-1-treated groups. c At 3-day post-injury, the number of $\mathrm{CD}^{+} \mathrm{CD}^{+} \mathrm{T}$ cells in the spinal cord was significantly higher in vehicle-treated animals compared to uninjured control group. There was no significant difference in the population of infiltrated helper $T$ cells and the number of FoxP3 ${ }^{+} \mathrm{T}_{\text {reg }}$ cells $\left(\mathrm{CD}^{+} \mathrm{CD}^{+} \mathrm{FoxP}^{+}\right)$between vehicle- and Nrg-1-treated groups. However, the population of IL-10 producing CD4 ${ }^{+} \mathrm{T}$ cells $\left(\mathrm{CD}^{+} \mathrm{CD}^{+} \mathrm{IL}-10^{+}\right)$was significantly increased in Nrg-1-treated animals in comparison to vehicle-treated group. $\mathbf{d}$ At 7 days post-SCl, despite no significant difference in the total helper and regulatory T cell populations between vehicle- and Nrg-1-treated groups, a significant reduction (1.9-fold) was observed in IFNy producing effector T cell population in Nrg-1-treated SCl rats compared to their vehicle-treated counterparts. e At 14 days post-SCl, infiltrated helper T cells reached their lowest level among all examined time-points, and Nrg-1 treatment had no significant effect on the total helper T cell population. IL-10 expressing $T_{\text {reg }}$ cells were significantly higher in both vehicle and Nrg-1 injured rats compared to uninjured animals. Nrg-1-treated animals showed a significantly higher number of $\mathrm{T}_{\text {reg }}$ cells in their spinal cord at 14-day time-point compared to vehicle-treated rats. $\mathbf{f}$ However, at chronic (42-day) time-point, the number of T helper cells reached a maximum, with Nrg-1-treated animals harboring a significantly decreased population of CD4 ${ }^{+} \mathrm{T}$-cells in their spinal cord compared to the vehicle-treated group. Most importantly, $\mathrm{CD} 3^{+} \mathrm{CD} 4^{+} \mathrm{FoxP} 3^{+}$and $\mathrm{CD} 3^{+} \mathrm{CD} 4^{+} \mathrm{IL}-10^{+}$regulatory $T$ cell populations were significantly increased in Nrg-1-treated groups. $\mathbf{g}$ Immunohistochemical images show the presence of $\mathrm{T}_{\text {reg }}$ cells in the perilesional area $\left(N=5 /\right.$ group/time-point, ${ }^{*} p<0.05,{ }^{* *} p<0.01,{ }^{* * *} p<0.001$, one-way ANOVA followed by Holm-Sidak post hoc test)
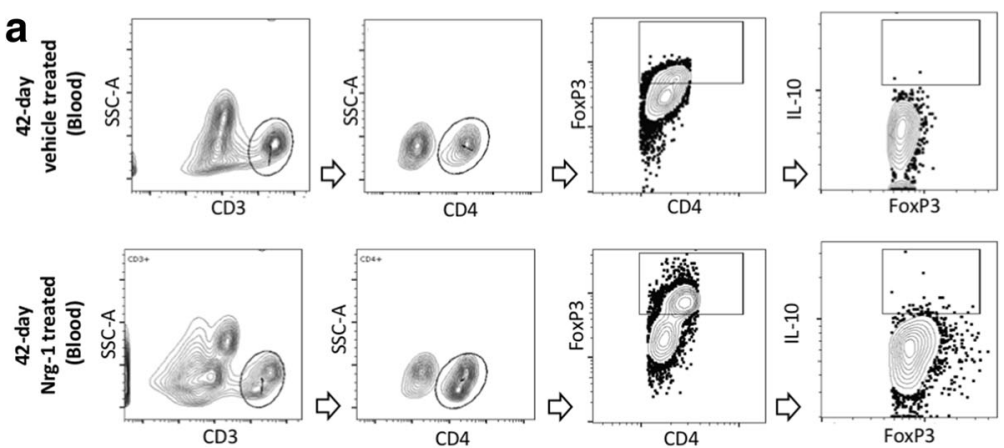

b
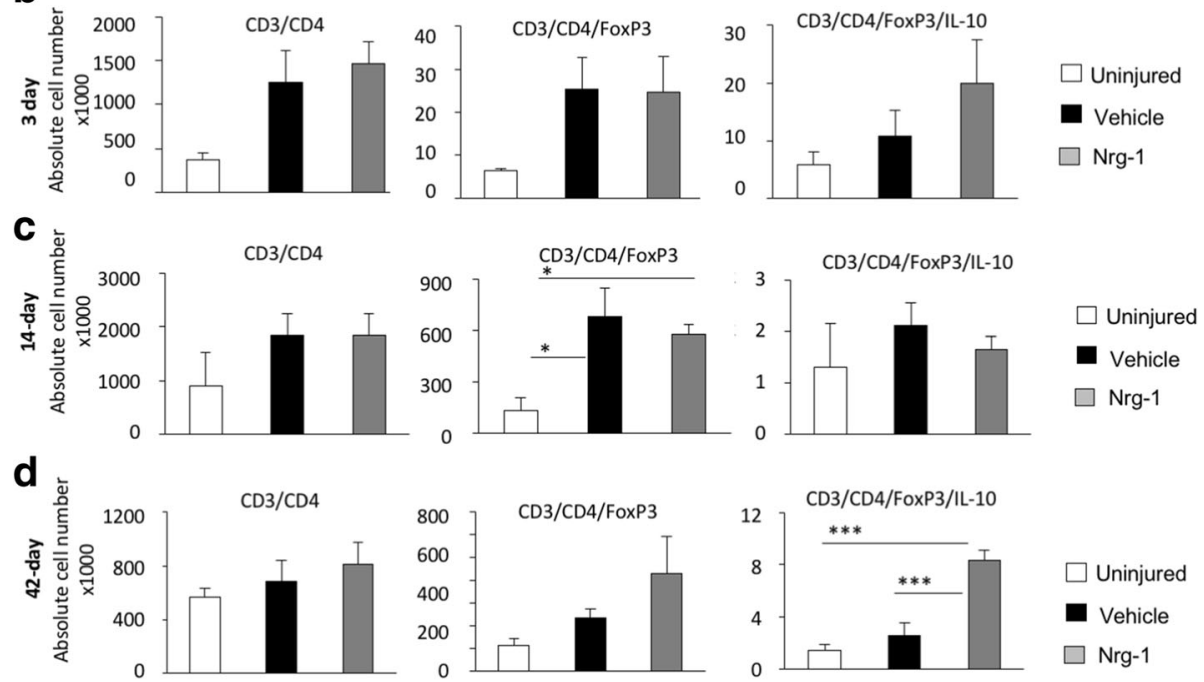

Fig. $3 \mathrm{Nrg}-1$ treatment increases the number of circulating $T_{\text {reg }}$ cells in the blood following chronic SCl. a Representative images are provided for the gating strategy for flow cytometric detection of $\mathrm{T}$ cells and their regulatory phenotype in the blood. b-d Flow cytometric analysis showed a slight increase in total $\mathrm{CD}^{+} \mathrm{CD}^{+}$helper $\mathrm{T}$ cell population upon injury. However, at all examined time-points, the total population of helper $\mathrm{T}$ cells was not significantly different among any of the studied groups $(p>0.05)$. The population of FoxP3 ${ }^{+}$helper $T$ cells was significantly increased at 14 days post-injury in the vehicle- and Nrg-1-treated rats as compared to the uninjured levels while there was no difference between the two injured groups. $\mathbf{d}$ At 42-day time-point, Nrg-1 treatment significantly increased the number of IL-10 expressing $\left(\mathrm{CD} 3^{+} \mathrm{CD} 4^{+} \mathrm{FoxP}^{+} \mathrm{IL}-10^{+}\right) \mathrm{T}_{\text {reg }} \mathrm{Cells}_{\mathrm{S}} \mathrm{compared}$ to vehicle and uninjured groups while there was no significant difference in the total population of helper and Fox $3^{+} \mathrm{T}$ cells between the vehicle and uninjured groups, ( $N=5 /$ group/time-point, ${ }^{*} p<0.05,{ }^{* *} p<0.01,{ }^{* * *} p<0.001$, one-way ANOVA followed by Holm-Sidak post hoc test) 

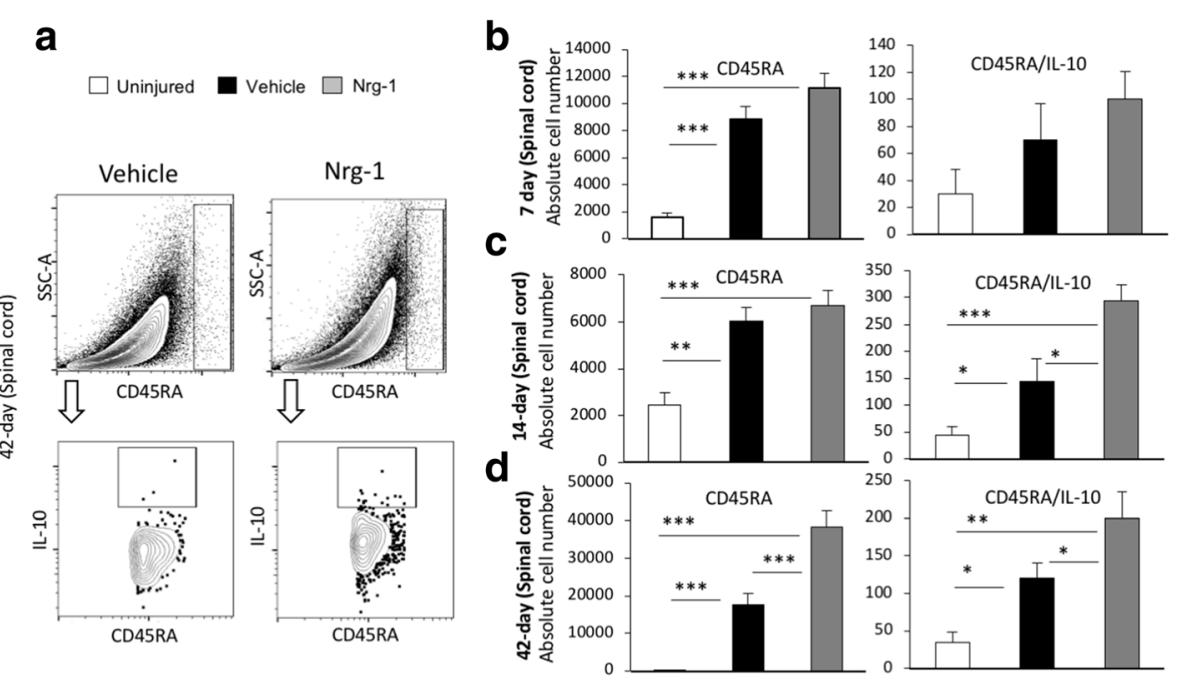

e
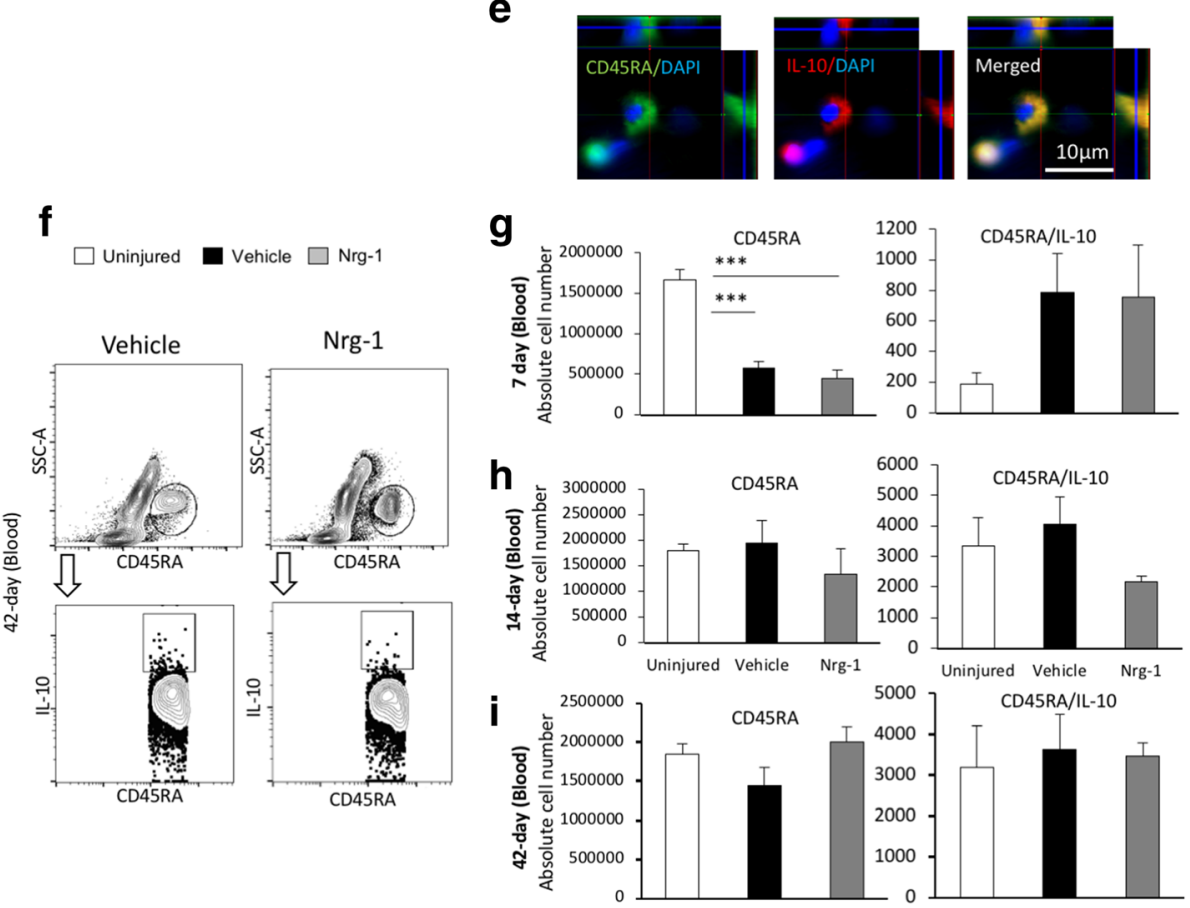

Fig. 4 Nrg-1 treatment promotes $B_{\text {reg }}$ cell population following SCl. a Representative images of the gating strategy for flow cytometry of spinal cord are provided. $\mathbf{b}$ At 7 days post-injury, the number of CD45RA ${ }^{+}$B cells was significantly increased in the spinal cord without any significant difference in the total and regulatory B cell populations between vehicle- and Nrg-1-treated groups. $\mathbf{c}$ At 14-day post-SCl, a significant increase in the number of $\mathrm{B}_{\text {reg }}$ cells was observed in Nrg-1-treated animals compared to vehicle-treated group. $\mathbf{d}$ Chronically at 42 days post-SCl, the number of B cells in the spinal cord reached the highest level compared to all earlier time-points. Nrg-1 treatment resulted in a significant increase in the number of infiltrated B cells in the spinal cord and promoted IL-10 expressing $B_{\text {reg }}$ cells compared to vehicle treatment. e Immunohistochemical analysis verified the presence of $B_{\text {reg }}$ cells in the perilesional area of the injured spinal cord. $\mathbf{f}$ Representative images of the gating strategy for flow cytometry of blood are provided. $\mathbf{g}$ Analysis of the blood revealed a significant decline in B cell population at 7 days post-SCI without any significant change in the Breg cell population at this time-point. h, i No significant change in total and regulatory B cell populations were observed in the blood at 14- and 42-day time-points. ( $N=5 /$ group/time-point, ${ }^{*} p<0.05,{ }^{* *} p<0.01,{ }^{* * *} p<0.001$, one-way ANOVA followed by Holm-Sidak post hoc test)

$\mathrm{CD} 45^{+} \mathrm{CD} 68^{+}$macrophages in the spinal cord compared to vehicle treatment (1.34 times).

We next performed immunophenotyping to determine whether Nrg-1 alters subpopulations of macrophages in the injured spinal cord. Our analysis of pro- inflammatory (M1) macrophages $\left(\mathrm{CD} 45^{+} \mathrm{CD} 68^{+} \mathrm{CD} 86^{+}\right)$ comparing uninjured and vehicle-treated injured rats showed an overall increase in M1 population at all examined time-points following SCI. This increase was statistically significant at 7,14 , and 42 days post-SCI 
Table 2 List of primers used in this study

Rat-IFN-g-F: ATT CAT GAG CAT CGC CAA GTT C

Rat-IFN-g-R: TGA CAG CTG GTG AAT CAC TCT GAT

Rat-IL6-F: TAG TCC TTC CTA CCC CAA CTT CC

Rat-IL6 R: TTG GTC CTT AGC CAC TCC TTC

Rat-CCL11-F: TGC TGC TTG AAC ACC TTG GA

Rat-CCL11-R: AGC CTG AAT ATT ACA GCT GGG T

Rat-CCL5-F: GCA GTC GTC TाT GTC ACT CG

Rat-CCL5-R: ATC CCC AGC TGG TTA GGA CT

Rat-IL10-F: TGC GAC GCT GTC ATC GAT TT

Rat-IL10-R: GTA GAT GCC GGG TGG TTC AA

Rat-CXCL1-F: CAA TGA GCT GCG CTG TCA GT

Rat-CXCL1-R: TTG AAG TGA ATC CCT GCC ACT

Rat-CXCL2-F: AGG GTA CAG GGG TTG TTG TG

Rat-CXCL2-R: CGA TCC TCT GAA CCA AGG GG

Rat-CXCL3-F: ACA TCC AGA GCT TGA CGG TG

Rat-CXCL3-R: TTG GAT GGA TCG CTG CTC TG

Rat-CXCL10-F: CCG CAT GTT GAG ATC ATT GCC

Rat-CXCL10-R: CTA GCC GCA CAC TGG GTA AA

Rat-NFKBIZ-F: GTG GAG GCG AAG GAT CGT AA

Rat-NFKBIZ-R: CAT CCA ACT GTG TCA CCC GA

$(p<0.01)$ (Fig. 1c-f). Compared to the baseline of SCI in vehicle-treated groups, Nrg-1 treatment had no apparent effect on the population of M1 macrophages at 3, 7, and 14-day time-points. However, the population of M1 macrophages was significantly increased (1.6-fold) in Nrg-1-treated animals at the chronic 42-day time-point compared to the vehicle group $(p<0.01)$ (Fig. 1f). Our phenotypic analysis revealed that Nrg-1 significantly increased the number of immunomodulatory $\left(\mathrm{CD} 45^{+} \mathrm{CD} 68\right.$ ${ }^{+} \mathrm{CD}_{163^{+}}$) M2 macrophages (3-fold) as well as their IL-10 expressing subpopulation $\left(\mathrm{CD} 45^{+} \mathrm{CD} 68^{+} \mathrm{CD} 163^{+} \mathrm{IL}-10^{+}, 4.1-\right.$ fold) at 3-day time-point. Moreover, we observed an increasing trend in the number of M2 macrophages at 7, 14, and 42-day time-points following Nrg-1 treatment, although these changes were not statistically significant. Using immunohistochemistry, we verified and confirmed the presence of $\mathrm{M} 1\left(\mathrm{CD}^{+} 8^{+} \mathrm{CD} 86^{+}\right)$and M2 $\left(\mathrm{CD}^{+} 8^{+} \mathrm{CD} 163^{+}\right)$macrophages in the perilesional area in the injured spinal cord (Fig. 1g). Altogether, our results indicate that systemic Nrg-1 treatment following SCI augments the recruitment of bloodborne macrophages to the spinal cord tissue at acute and chronic stages with an increase in M2 phenotype at acute (3-day) and M1 phenotype during chronic (42-day) stage of SCI (Fig. 1c, f, verification of antibody specificity and gating strategy are shown in Additional file 1: Figure S1).

\section{Neuregulin-1 promotes a regulatory $\mathrm{T}$ cell response in the blood and spinal cord following $\mathrm{SCl}$}

We next studied how systemic Nrg-1 infusion affects T cell response in the peripheral blood and within the injured spinal cord. $\mathrm{T}$ cells orchestrate the adaptive immune response following SCI [19] with differential roles through their diverse production of pro- and antiinflammatory cytokines and chemokines [20]. Using the same time-points described above, our flow cytometric analysis of the spinal cord tissue in baseline vehicle SCI rats showed an overall significant increase in the population of infiltrated helper $\mathrm{T}$ cells $\left(\mathrm{CD} 3^{+} \mathrm{CD} 4^{+}\right)$in the injured spinal cord at $3,7,14$, and 42 days post-injury by 7.7-, 16.3-, 4.5-, and 13.5-folds, respectively $(p<0.01$ at 3 -day and $p<0.001$ at all later time-points). Interestingly, while $\mathrm{CD}^{+} \mathrm{CD}^{+}$helper $\mathrm{T}$ cells were significantly present at all stages of SCI, we found a decline in their number subacutely on day 14 post-injury. However, this decline was followed by an increase in their population reaching a maximum at the chronic stage of SCI on day 42 (13.5 times increase) $(p<0.001)$ (Fig. 2c-f). The biphasic baseline pattern of $\mathrm{T}$ cell recruitment after SCI is in agreement with previous studies [1]. Nrg-1 treatment had no apparent effect on the population of helper $\mathrm{T}$ cells in acute and subacute SCI, whereas it significantly reduced their recruitment in the chronic SCI at the 42-day time-point.

We next performed immunophenotypic analysis within the $\mathrm{CD}^{+} \mathrm{CD}^{+}$helper $\mathrm{T}$ cell population to determine whether Nrg-1 treatment can alter T cell subsets in the injured spinal cord. Our analysis showed that SCI promotes $\mathrm{T}$ regulatory $\left(\mathrm{T}_{\text {reg }}\right)\left(\mathrm{CD}^{+} \mathrm{CD}^{+} \mathrm{FoxP}^{+}\right.$and $\mathrm{CD}^{+} \mathrm{CD} 4^{+} \mathrm{IL}-10^{+}$) subpopulation after SCI. Nrg-1 treated SCI animals had a significantly higher population of $\mathrm{T}_{\text {reg }}$ cells at 3 days (3.5-folds, $\left.p<0.01\right), 14$ days (5.6-folds, $p<0.01)$, and 42 days (1.8-folds, $p<0.05)$ time-points compared to vehicle-treated (Fig. 2c-f). Analysis of $\mathrm{T}$ effector $\left(\mathrm{T}_{\text {eff }}\right)$ cell subpopulation (CD3 ${ }^{+} \mathrm{CD} 4{ }^{+}$IFN- $\gamma^{+}$) also showed a remarkable positive effect for Nrg-1 in modulating $\mathrm{T}$ cell response in subacute SCI. At 7 days post-injury, compared to the uninjured group, $\mathrm{SCI}$ induced a significant increase in $\mathrm{T}_{\text {eff }}$ cells within the injured spinal cord of vehicle-treated rats (100-fold, $p<0.001)$ which was significantly reduced by Nrg-1 treatment to nearly $50 \%$ (Fig. $2 \mathrm{~d}$ ). At other time-points, no significant change in $\mathrm{T}_{\text {eff }}$ cell subpopulation was detected under Nrg-1 treatment (data not shown). Our immunohistochemical assessments verified the presence of CD3 ${ }^{+}$FoxP3 ${ }^{+} \mathrm{IL}_{10}{ }^{+} \mathrm{T}_{\text {reg }}$ cells in the perilesional area of the injured spinal cord (Fig. 2g).

We further investigated the systemic effects of $\mathrm{Nrg}-1$ on $\mathrm{T}$ cell recruitment and phenotype in the blood following SCI by flow cytometric analysis (Fig. 3). We observed an increasing trend in the population of helper $\mathrm{T}$ cells $\left(\mathrm{CD}^{+} \mathrm{CD}^{+}\right)$in the blood of SCI animals. However, this increase was not statistically significant at any of the examined time-points, and Nrg-1 treatment had no apparent effect on the population of helper $\mathrm{T}$ cells after SCI (Fig. 3b-d). Our analysis of $\mathrm{CD} 3^{+} \mathrm{CD} 4^{+}$FoxP3 ${ }^{+} \mathrm{IL} 10^{+}$cells also showed no change in the population of 
Treg cells in the blood under the baseline of SCI. While Nrg-1 treatment had no noticeable effect on $\mathrm{T}_{\text {reg }}$ cell population in the blood at 3 and 14 days post-SCI, it stimulated a significant (3.7-fold) increase in the number of $\mathrm{IL}-10$ expressing $\mathrm{T}_{\text {reg }}$ cells $\left(\mathrm{CD}^{+}{ }^{+} \mathrm{CD} 4^{+} \mathrm{FoxP}^{+} \mathrm{IL}^{-10^{+}}\right)$ chronically at 42 days post-injury compared to their vehicle-treated counterparts (Fig. 3d, verification of antibody specificity and gating strategy are shown in Additional file 1: Figure S2). In conclusions, our analysis of $\mathrm{T}$ lymphocyte response demonstrates the ability of Nrg-1 to promote the population of immune-modulatory $\mathrm{T}_{\text {reg }}$ cells in the blood and spinal cord after SCI.

\section{Nrg-1 treatment is associated with an increase in regulatory $B$ cell phenotype following $\mathrm{SCl}$}

B cells contribute to SCI secondary tissue damage after SCI by producing cytokines and autoantibodies [10, 21]. Despite their detrimental roles in tissue degeneration, $\mathrm{B}$ cells have the ability to positively modulate immune response through adopting an IL-10 producing immune regulatory $\left(\mathrm{B}_{\mathrm{reg}}\right)$ phenotype [22]. Our flow cytometric analysis showed that SCI triggers the recruitment of $B$ cells to the spinal cord. We found a significant increase in the total number of CD45RA ${ }^{+} \mathrm{B}$ cells in the vehicletreated injured spinal cord at all examined time-points compared to uninjured group (5.4-fold at 7-day, 2.4-fold at 14-day, and 61-fold at 42-day) ( $p<0.01)$ (Fig. 4b-d). While Nrg-1 treatment did not alter B cell infiltration at the subacute 7-day and 14-day time-points, it significantly induced B cell recruitment to the injured spinal cord chronically at the 42-day time-point (2.1-fold, $p<0.001)$ compared to vehicle-treated group (Fig. 4d). Analysis of $B_{\text {reg }}$ cells subpopulation (CD45RA $\left.{ }^{+} \mathrm{IL}-10^{+}\right)$in the spinal cord tissue showed the ability of Nrg-1 treatment to significantly promote IL-10 producing $\mathrm{B}_{\text {reg }}$ population at 14 days (2-folds) and 42 days (1.6-folds) post-SCI $(p<0.05)$ compared to vehicle treatment (Fig. 4c, d). Presence of CD45RA ${ }^{+} \mathrm{IL}_{10}{ }^{+}$cells in the perilesional area of the injured spinal cord was verified in our immunohistochemical analysis (Fig. 4e). Interestingly, our flow cytometric analysis showed a significant threefold reduction in $\mathrm{CD}_{45 \mathrm{RA}}^{+} \mathrm{B}$ cell population in the blood at 7-day post-SCI in both vehicle- and Nrg-1-treated SCI rats compared to uninjured control group $(p<0.001)$, which was recovered to the normal baseline by the 14-day time-point (Fig. $4 \mathrm{~g}, \mathrm{~h}$ ). This observation is in line with other studies that reported a transient cessation of $\mathrm{B}$ lymphopoiesis in the bone marrow following SCI [23]. Nonetheless, there was no significant difference in the number of circulating $\mathrm{B}_{\text {reg }}$ cells in the blood between vehicle- and Nrg-1treated animals at any examined time-point (Fig. 4g-i, verification of antibody specificity and gating strategy are shown in Additional file 1: Figure S3). Altogether, our data show that systemic administration of Nrg-1 induces a $B_{\text {reg }}$ cell response following SCI only at the level of spinal cord tissue without affecting the phenotype of circulating B cells.

\section{Nrg-1 treatment positively modulates inflammatory cytokine expression following $\mathrm{SCl}$}

We previously showed that intrathecal infusion of Nrg-1 reduces the level TNF- $\alpha$ and IL- $1 \beta$ in the injured spinal cord [13]. Here, we extended these initial findings to investigate the effect of systemic Nrg-1 treatment on the expression of several key inflammatory cytokines involved in the regulation of immune response following SCI including IFN- $\gamma$, IL-6, IL-12, and IL-10 [24-27]. Our real-time qPCR analysis of IFN- $\gamma$ expression, a proinflammatory cytokine involved in M1 macrophage activation, and cytotoxic $\mathrm{T}$ cell proliferation [28, 29], showed a significant 6.5- and 12-fold increase at 7-day and 42-day time-points, respectively, in vehicle-treated rats as compared to uninjured group (Fig. 5a). Interestingly, Nrg-1 treatment significantly attenuated IFN- $\gamma$ expression subacutely at 7 days post-SCI by $47 \%$ compared to vehicle treatment with no apparent effect at the 42-day chronic time-point $(p<0.01)$ (Fig. 5a). Next, we assessed the expression of the pro-inflammatory cytokine IL-6 which is known to induce cellular injury and tissue degeneration following SCI [30]. IL-6 expression was transiently and significantly increased (5.1-fold) at 3 days after injury in vehicle-treated animals compared to uninjured control group and returned to its normal baseline levels at 7 days post-SCI and onwards (Fig. 5b). Nrg-1-treated animals showed a significant 2.4-fold reduction in IL-6 expression in their injured spinal cord at acute 3 -day time-point $(p<0.05)$ (Fig. 5b). There was no significant difference in IL- 6 expression between the vehicle- and Nrg-1-treated animals at any later timepoint $(p>0.05)$ (Fig. 5b). Expression of IL-12A, a pro-inflammatory cytokine involved in microglia/macrophage activation with both beneficial and detrimental roles [26, 31], was also significantly elevated at subacute 7-day post-injury (2.4-fold) which remained upregulated up to the chronic 42-day time-point $(2.7$-fold $) \quad(p<0.05)$ (Fig. 5c). Nrg-1 treatment was not associated with any significant change in IL-12A expression at any stage after SCI (Fig. 5c).

Given Nrg-1 promoted an IL-10 regulatory phenotype in macrophages and lymphocytes, we also assessed IL-10 transcript expression. Seven days after injury, the expression of IL-10 increased significantly (8.3-fold) in the injured spinal cord (Fig. 5d). In agreement with our flow cytometry data, Nrg-1 treatment resulted in a significantly higher (2.6-fold) expression of IL-10 


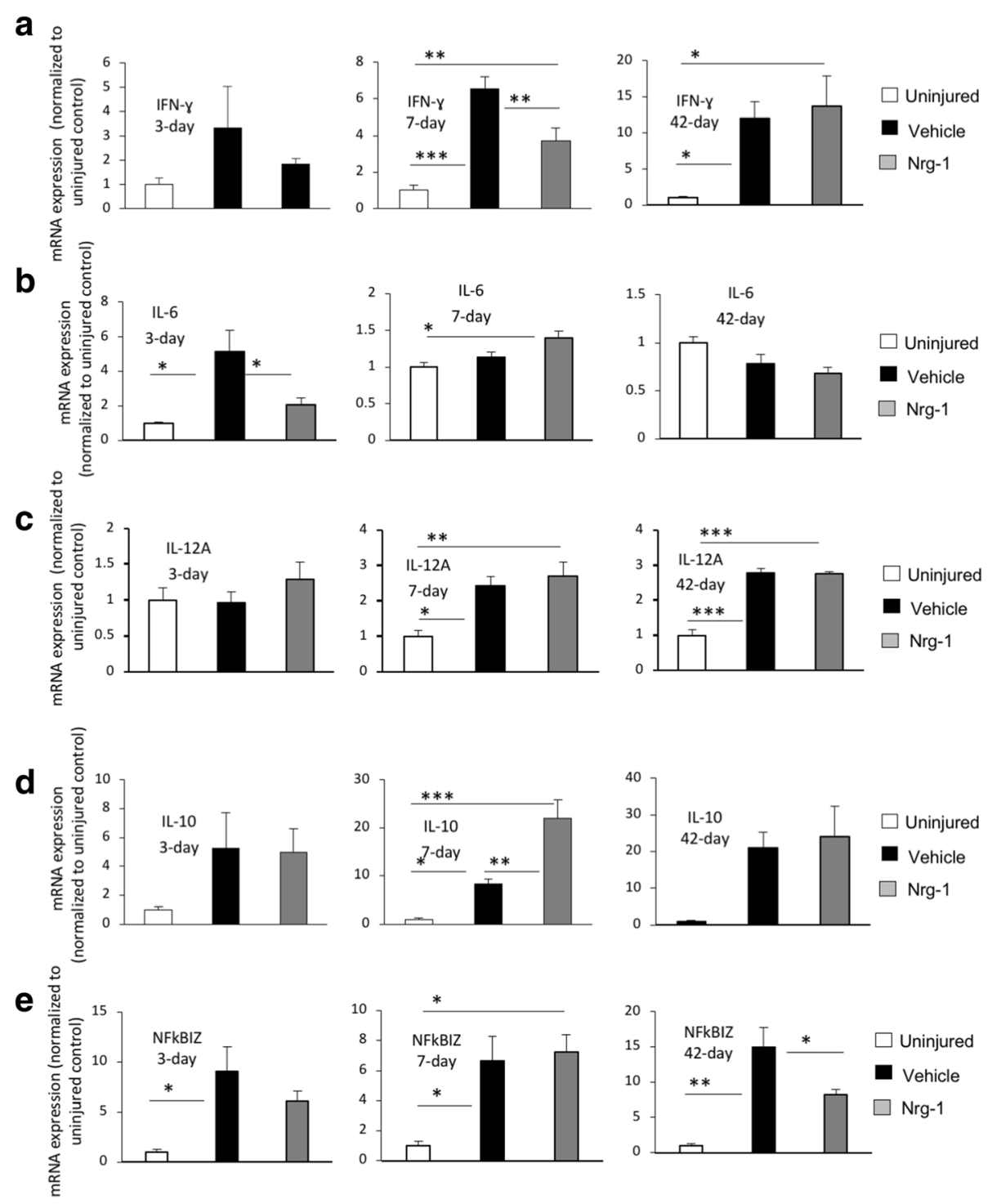

Fig. 5 Nrg-1 treatment regulates inflammatory cytokines in the injured spinal cord. a Transcript analysis of the spinal cord tissue using real-time QPCR released a significant increase in expression of IFN- $\gamma$ at 7-day post-injury $(p<0.001)$. Nrg-1 treatment significantly decreased the SCI-induced expression of IFN- $\gamma$ in the injured spinal cord tissue. $\mathbf{b}$ Expression of IL-6 was significantly increased at 3 days post-injury, which was significantly attenuated by Nrg-1 treatment $(p<0.05)$. No significant difference in IL-6 expression was observed between vehicle- and Nrg-1-treated groups at 7- and 42-day time-points. c IL-12A was significantly increased at 7 days post-injury and remained significantly elevated until 42 days. Nrg-1 had no significant effect on IL-12A expression at any examined time-point. $\mathbf{d}$ Transcript levels of IL-10 were significantly increased at 7 days post-injury. Interestingly, Nrg-1-treated animals showed a significantly higher expression of IL-10 compared to the vehicle group at this time-point. No significant change in IL-10 expression was observed at any other examined time-points. e NFkBIZ transcript level was significantly elevated at 3 days and reached

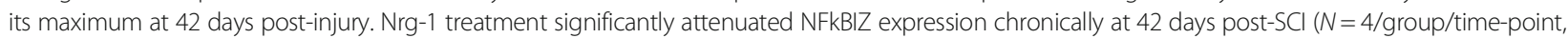
${ }^{*} p<0.05,{ }^{* *} p<0.01,{ }^{* * *} p<0.001$, one-way ANOVA followed by Holm-Sidak post hoc test)

compared to vehicle treatment (Fig. 5e). Change in IL10 expression was more pronounced in subacute stage of SCI (Fig. 5d).

Finally, we investigated the expression of $N F \kappa B$ inhibitor zeta (NFkBIZ or I $\mathrm{K} B$ ), an atypical IkB which is known to be an essential activator of IL-6 expression and acts as a transcription co-activator of proinflammatory cytokines such as IL-12 [32, 33]. The expression of NFkBIZ was significantly increased at 3 and 7 days post-injury (9- and 6.6-fold, respectively) and reached its maximum at 42-day time-point (14.9fold) (Fig. 5e). This elevation was reduced significantly (45\%) by Nrg- 1 treatment chronically at 42 days postinjury (Fig. 5e). NFkBIZ expression was also reduced by Nrg-1 treatment acutely; however, the effect was not statistically significant. Altogether, these results show a 
positive role for Nrg-1 in regulating inflammatory cytokine profile of the injured spinal cord tissue which seemed to be modulated, at least in part, by NFKB pathway following SCI.

\section{Pro-regenerative modulation of chemokine expression by} Nrg-1 treatment following $\mathrm{SCl}$

In addition to cytokine assessment, we sought to determine the effect of systemic Nrg-1 treatment on chemokine profile in the spinal cord tissue. We focused on $\mathrm{C}-\mathrm{C}$ motif ligands (CCL) 5 and 11 and C-X-C motif ligands (CXCL) 1, 2, 3, and 10 that are involved in the pathophysiology of SCI [34-39].

\section{Effects of Nrg-1 on the expression of CCL 5 and 11}

C-C motif chemokine 5 (CCL5 or RANTES) is produced by resident glial and peripherally recruited immune cells including $\mathrm{T}$ cells, macrophages, and astrocytes and is known to induce neuroinflammation by attracting leukocytes to the site of injury $[40,41]$. The increased CCL5 level has been associated with microvascular dysfunction and tissue damage following CNS injury [42]. At 3-day post-SCI, the expression of CCL5 was increased (Fig. 6a). However, this increase was not statistically significant, and Nrg-1 treatment had no apparent effect on CCL5 expression acutely. At 7 and 42 days post-SCI, CCL5 expression in the spinal cord was remarkably increased by 12 - and 16-folds, respectively, compared to uninjured animals $(p<0.01)$. Nrg-1-treated animals demonstrated a significant $47 \%$ reduction in CCL5 expression at 7 days post-SCI with an insignificant $24 \%$ decline at 42 -day chronic time-point $(p<0.01)$ (Fig. 6a).

CCL11 or eotaxin-1 is a small chemokine that is mainly produced by macrophages and neurons with positive effects in CNS injury including tightening the blood-brain barrier and fostering a Th2 immunomodulatory response [39]. CCL11 is also considered a pro-regenerative chemokine by promoting proliferation and migration of neural progenitor cells [43]. Our qPCR analysis of the spinal cord tissue at 3- and 7-day time-points in both vehicle- and Nrg-1-treated animals showed no significant change in CCL11 expression (Fig. 6b). However, at the chronic 42-day time-point, SCI baseline expression of CCL11 reached a significant 6.8-fold increase compared to the uninjured control group (Fig. 6b). Interestingly, Nrg-1 treatment induced a significant $37 \%$ increase in CCL11 expression compared to vehicle treatment (Fig. 6b).

\section{Effects of systemic Nrg-1 treatment on the expression of CXC family of chemokines}

CXCL1, 2, 3, and10 play a substantial role in SCI neuroinflammation and induction of neuropathic pain [36, 44]. CXCL1 and CXCL2 are produced by mast cells and macrophages and control neutrophil recruitment during tissue inflammation [45]. Using $\mathrm{qPCR}$, we observed a significant increase in the expression of CXCL1 and CXCL2 at 3 days post-injury (10- and 16-folds, respectively). Nrg-1 treatment significantly reduced the expression of both chemokines acutely (74 and 64\% decrease, respectively) (Fig.6c, d). There was no significant change in the expression of CXCL1 at subacute and chronic time-points. However, the expression level of CXCL2 was significantly increased at the 42-day chronic timepoint compared to uninjured control group (8.5-fold), although Nrg-1-treated animals showed no significant change in the expression of CXCL2 compared to vehicle-treated group at this time-point (Fig. 6d). Next, we assessed the expression of CXCL3, which is a ligand for CXC chemokine receptor (CXCR) 2 [34]. It has been shown that inhibition of CXCR2 attenuates neuroinflammation and improves tissue preservation following $\mathrm{SCI}$ [34]. CXCL3 expression was increased significantly at the acute 3-day (3.9-fold) and chronic 42-day (15.2-fold) post-injury (Fig. 6e). Nrg-1 treatment remarkably decreased (96\%) the expression of CXCL3 at the 42-day time-point.

CXCL10 is another member of CXC family of chemokines which is known for its distinct role in $\mathrm{T}$ cell recruitment and exacerbation of secondary tissue degeneration following SCI [35]. Neutralization of CXCL10 has been associated with better structural and functional outcomes following SCI [35]. Following injury, expression of CXCL10 was increased as early as 3 days postSCI. However, this increase was only statistically significant at the chronic 42-day post-injury (34-fold increase) compared to uninjured group (Fig. 6f). Similar to the other examined CXCL chemokines, Nrg-1-treated animals showed a significant 36\% decrease in CXCL10 expression chronically (Fig. 6f). Taken together, these results demonstrate that $\mathrm{Nrg}-1$ treatment can positively modulate the repertoire of cytokines and chemokines in the spinal cord tissue following SCI. Importantly, our expression data, in agreement with our flow cytometry data, indicate a more prominent role for Nrg-1 in modulating neuroinflammation at the chronic stage of SCI.

\section{Systemic Nrg-1 treatment decreases IgM and lgG deposition in the injured spinal cord acutely}

Following SCI, autoantibodies are produced by B cells against spinal cord neoepitopes and contribute to neuroinflammation and secondary tissue damage [21]. Since we identified a role for Nrg-1 in regulating B cell response in SCI, we sought to study antibody deposition in the injured spinal cord. We performed immunohistochemical analysis of IgM and IgG in the injured spinal cord, spanning $6 \mathrm{~mm}$ of injured tissue around the injury epicenter rostrally and caudally. At 7 days post-injury, we found a significant reduction in IgM deposition in 


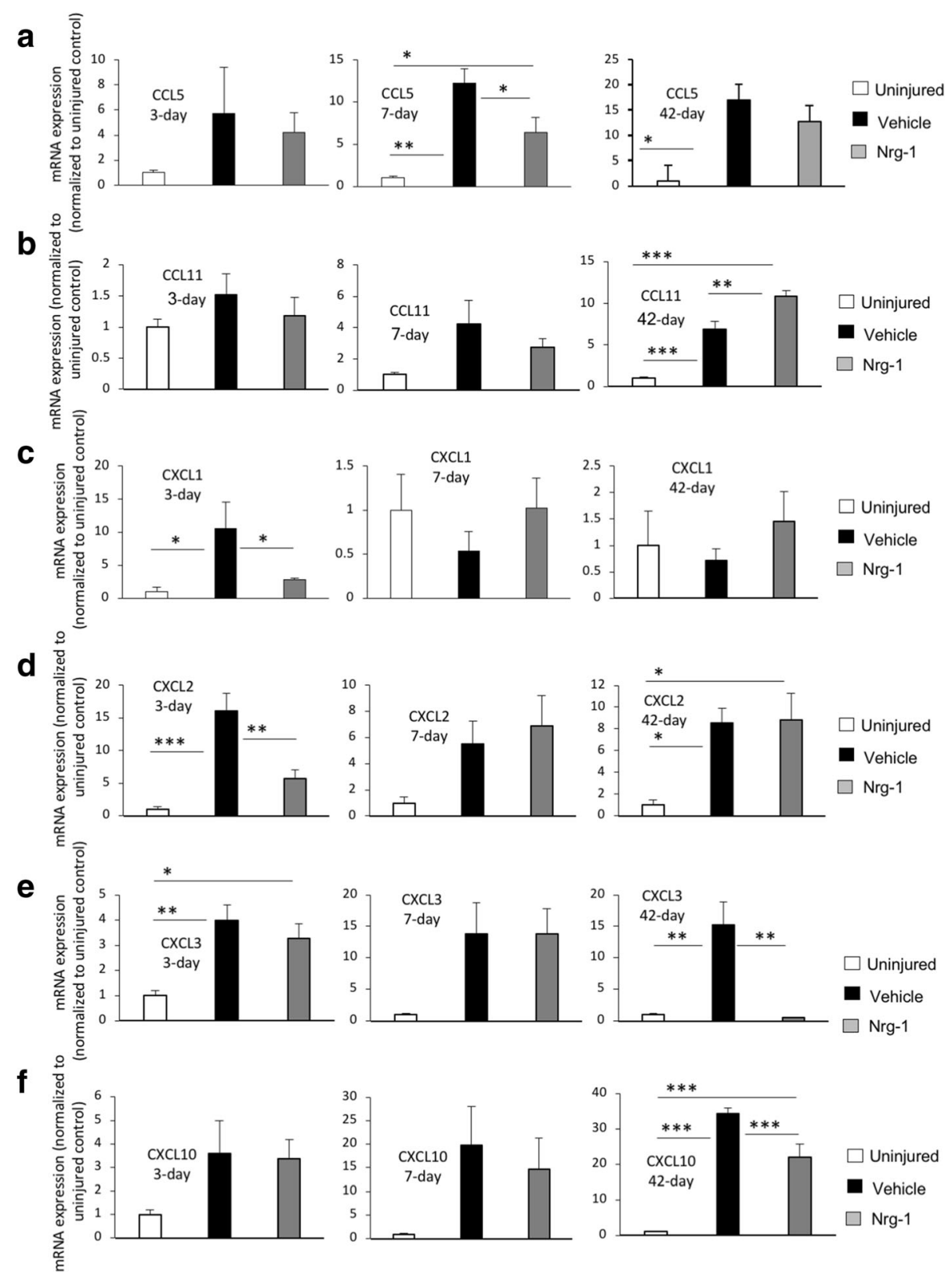

Fig. $6 \mathrm{Nrg}-1$ treatment positively modulates chemokine expression following SCl. a Analysis of chemokine expression in the spinal cord tissue was performed using real-time aPCR. There was a significant increase in the expression of pro-inflammatory chemokine CCL5, at 7-day post-injury, which was significantly reduced by Nrg-1 treatment. CCL5 mRNA level reached its maximum level at 42 days post-injury. However, no significant difference was found between vehicle- and Nrg-1-treated animals at this time-point. b Although the expression of CCL11, an immune modulatory chemokine, was not significantly changed at 3 and 7 days post-injury, it underwent a significant increase chronically at 42-day time-point. Nrg- 1 treatment was able to significantly increase CCL11 expression compared to vehicle-treated group. c, $\mathbf{d}$ Expression of pro-inflammatory chemokines CXCL1 and CXCL2 was significantly elevated at 3-day post-injury. Nrg-1 treatment significantly reduced CXCL1 and CXCL2 expressions at this time-point. The overall tissue level of CXCL1 mRNA reached baseline levels at 7-day post-injury and remained stable until 42 days post-injury. CXCL2 expression, however, remained elevated at 7 and 42 days post-injury compared to uninjured group (significant 8.5-fold increase at 42-day). Nrg-1 treatment had no significant effect on CXCL2 expression at 7 and 42-day time-points. e Expression of the pro-inflammatory chemokine CXCL3was significantly upregulated 3 days after injury and reached its maximum levels chronically at 42 days post-SCI $(p<0.01)$. Nrg-1-treated animals showed a significant reduction in CXCL3 expression at 42-day time-point (31 times). $\mathbf{f}$ CXCL10 expression was not significantly changed following an injury at 3 and 7 days post-SCl, while it was significantly increased in the vehicle-treated group compared to un-injured animals at 42 days. Nrg-1 significantly decreased CXCL 10 expression at this time-point $(p<0.001)\left(N=4 /\right.$ group/time-point, ${ }^{*} p<0.05,{ }^{* *} p<0.01,{ }^{* * *} p<0.001$, one-way ANOVA followed by Holm-Sidak post hoc test) 
the Nrg-1-treated group as compared to vehicle-treated rats. This reduction was significant at the epicenter (163-fold), 1- and 2-mm rostral (1.8- and 2.2-fold, respectively) as well as 1 -mm caudal (1.8-fold) points to the injury epicenter $(p<0.05$, two-way ANOVA, $N=5 /$ group) (Fig. 7a). In a similar immunointensity analysis, we also found a reduction in IgG deposition in the spinal cord of Nrg-1-treated animals compared to vehicletreated group. This reduction was statistically significant at $1 \mathrm{~mm}$ rostral to the injury epicenter (Fig. 7b). Analysis of IgG and IgM deposition at the chronic 42-day timepoint showed no significant difference between vehicleand Nrg-1-treated groups (Fig. 7c, d). These results show the ability of Nrg-1 to reduce antibody deposition at subacute stage of SCI and a plausible mechanism through which Nrg-1 improved neural tissue preservation in our previous studies.

\section{Discussion}

In the current study, using a clinically relevant model of compressive/contusive SCI in rats, we have identified a novel positive immunomodulatory role for Nrg-1 in SCI. Systemic Nrg-1 therapy augments regulatory populations of macrophages, $T$ cells, and $B$ cells both peripherally and in the injured spinal cord tissue during the acute and chronic phases of SCI. Moreover, Nrg-1 treatment promotes pro-regenerative immune mediators such as IL-10 and CCL11 while attenuating pro-inflammatory cytokines and chemokines, IL-6, IFN- $\gamma$, CXCL1, CXCL2, and CXCL3. Importantly, Nrg-1 positively regulates B
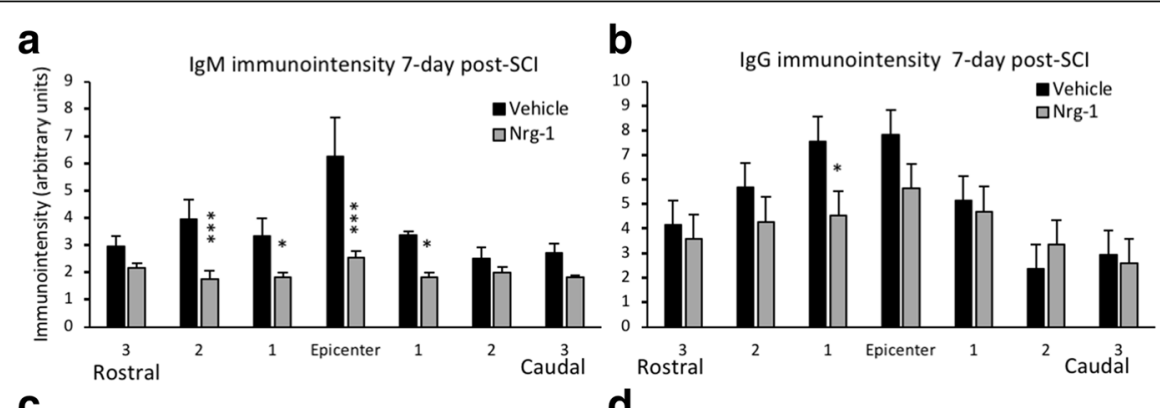

d
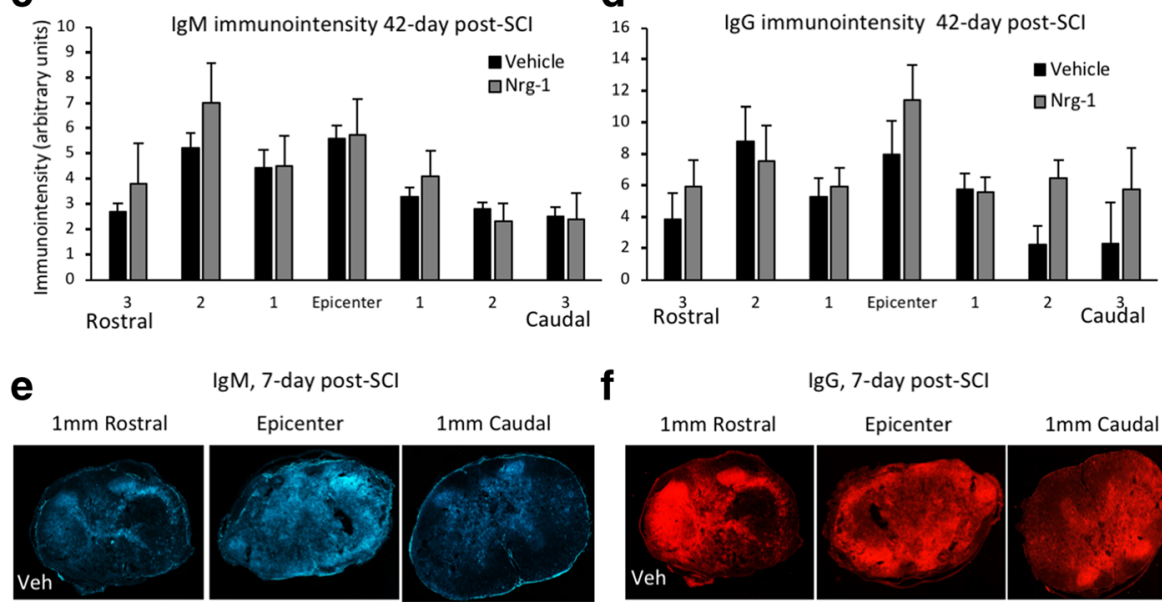

IgM, 7-day post-SCI

f

Epicenter $\quad 1 \mathrm{~mm}$ Caudal

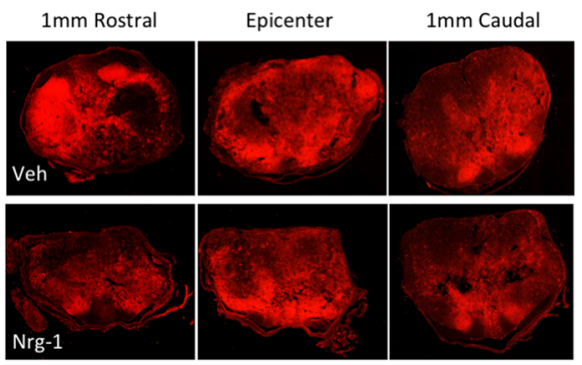

Fig. 7 Nrg-1 therapy significantly attenuates antibody deposition in the injured spinal cord tissue at subacute stage of SCl. a-d Immunohistochemical assessment of injured spinal cord tissue for lgM and lgG deposition was performed at the epicenter and perilesional areas at subacute (7 days) and chronic (42 days) stages of SCl. a, c Analysis of IgM immunointensity showed a significantly lower lgM deposition in Nrg-1-treated animals compared to vehicle-treated group at 7-day post-SCl. This decrease was significant at the epicenter, $1 \mathrm{~mm}$ caudal and 1 and $2 \mathrm{~mm}$ rostral to the injury site. No significant difference in IgM deposition was detected at 42-day time-point. $\mathbf{b}$, $\mathbf{d}$ Comparison of IgG immunointensity between the vehicle- and Nrg-1-treated animals revealed a significant decrease in lgG deposition only at $1 \mathrm{~mm}$ rostral to the epicenter at 7-day post-injury. No significant difference was detected in IgG deposition between the vehicle- and Nrg-1-treated groups at 42-day time-point. e, $\mathbf{f}$ Representative images are provided at the epicenter and $1 \mathrm{~mm}$ rostral and caudal to the lesion center $\left(\mathrm{N}=4 / \mathrm{group} /\right.$ time-point, ${ }^{*} p<0.05$, ${ }^{* *} p<0.01,{ }^{* * *} p<0.001$, two-way ANOVA followed by Holm-Sidak post hoc test) 
cell activity and moderates SCI-induced deposition of IgG and IgM in the spinal cord. To our knowledge, this is the first study that investigates the impact of Nrg-1 on neuroinflammation in traumatic SCI. Importantly, we have demonstrated the potential of systemic Nrg-1 as a new promising immunomodulatory strategy for traumatic SCI in a clinically relevant model. Of note, the Nrg-1 treatment used in our study is shown to pass the blood-brain and spinal cord barrier and enter the central nervous system (CNS) readily [46] and importantly has shown therapeutic efficacy in previous studies by our group and others [13, 47].

Nrg-1 and ErbB network is known for its critical role in the developing central and peripheral nervous systems [48]. In the spinal cord, while the implication of Nrg-1 in neural differentiation and myelination is established during development $[49,50]$, our knowledge on the role of Nrg-1 in SCI pathophysiology and neuroinflammation is still in its infancy. In recent years, work by our group and others has begun unraveling the importance of Nrg1 in the pathologic CNS [11, 13-15]. We originally identified that Nrg-1 protein expression is severely depleted in acute traumatic SCI and remains down-regulated chronically [11]. We established a close correlation between Nrg-1 dysregulation and impaired endogenous precursor response after SCI [11]. Restoration of Nrg-1 was sufficient to activate an endogenous repair program that promoted oligodendrocyte replacement and white matter repair following SCI $[11,13]$. A recent study has also shown an essential role for Nrg-1 in Schwann cell driven remyelination after SCI that is known to be instrumental for endogenous myelin repair in the injured spinal cord [12]. Interestingly, we found that Nrg-1 treatment exerts a prominent neuroprotective effect on oligodendrocytes and axons after SCI [11], which complements the recent reports showing increased neuronal survival following ischemic brain insult [15]. In addition to the anticipated impact of Nrg-1 on oligodendrocytes and myelination, our recent in vitro and in vivo studies uncovered a novel role for $\mathrm{Nrg}-1$ in regulating astrocyte response to injury and evolution of the glial scar in the injured spinal cord [13]. More specifically, Nrg-1 treatment had a remarkable effect on matrix remodeling in the glial scar by moderating the SCI-induced upregulation of chondroitin sulfate proteoglycans (CSPGs), a key regulator of SCI pathophysiology and a master inhibitor of repair processes [51]. We unraveled that Nrg-1 mediates its effects through activation of ErbB2/3 complex in glial cells and an increase in phosphorylation of Erk $1 / 2$ and STAT3 pathways following SCI [13]. Most importantly, we showed that Nrg-1 treatment improves neurobehavioral recovery in a dose-dependent manner after SCI [13]. Interestingly, these studies also provided the initial evidence for immunomodulatory effects of Nrg-1, which seems to be an underpinning mechanism for its beneficial effects in SCI.

We and others have demonstrated that Nrg-1 positively influences microglia in vitro and attenuates their response to stressful conditions as evidenced by the reduced production of pro-inflammatory mediators such as nitric oxide (NO), IL-1 $\beta$, and TNF- $\quad[13,52]$. In rat $\mathrm{SCI}$, we found that intrathecal Nrg-1 treatment can remarkably enhance an IL-10 dominant cytokine balance [13] that is shown to be beneficial for SCI repair processes such as remyelination [53]. Several immune regulatory populations such as $\mathrm{T}_{\text {reg }}$ cells, $\mathrm{B}_{\text {reg }}$ cells, and M2 microglia/macrophages produce IL-10 after SCI suggestive of a broader role for Nrg-1 in modulating neuroinflammation [54-56]. Notably, $\mathrm{T}$ and B lymphocytes, macrophages, and microglia express Nrg-1 receptors [13, 57-59], and therefore, all these populations can potentially be affected by the dysregulation of Nrg-1 signaling following SCI. To date, the role of Nrg-1 in modulating the innate and adaptive immune response in SCI has remained elusive. In this study, we employed systemic Nrg-1 delivery to understand how Nrg-1 influences the recruitment and function of immune cells not only within the injured spinal cord tissue but also in the peripheral blood. Additionally, systemic delivery provides a more clinically relevant therapeutic strategy for SCI.

Our immunophenotypic investigation of the injured spinal cord tissue revealed that systemic Nrg-1 increases macrophage infiltration into the injured spinal cord, which seems to be temporally regulated. We found that Nrg-1 promotes the recruitment of macrophages acutely and chronically with no apparent effect at the subacute stage. Interestingly, previous studies on acute peripheral nerve injury have also shown that intrathecal infusion of Nrg-1 induces recruitment and proliferation of resident microglia in the dorsal horn where injured sensory afferents enter the spinal cord $[60,61]$. Increased microgliosis and macrophage proliferation in response to over-activation of Nrg-1 and ErbB receptors have been also shown in direct in vitro studies $[60,61]$. Although Nrg-1-induced microgliosis has been associated with neuropathic pain in peripheral nerve injury [60,61], our previous studies in rat SCI showed no significant change in pain sensation following Nrg-1 treatment [13]. It is noteworthy that Nrg-1 treatment in our SCI studies augments the downregulated levels of Nrg-1 in the injured spinal cord as opposed to over-activating its signaling. Interestingly, although Nrg-1 increased the population of macrophages in acute SCI, this increase mainly reflected an elevation in the subpopulation of alternatively activated $\mathrm{M} 2$ macrophages $\left(\mathrm{CD} 45^{+} \mathrm{CD} 68^{+} \mathrm{CD} 163\right.$ ${ }^{+} \mathrm{IL} 10^{+}$) with no change in the population of classically activated pro-inflammatory $\mathrm{M} 1\left(\mathrm{CD} 45^{+} \mathrm{CD} 68^{+} \mathrm{CD} 86^{+}\right)$ 
macrophages. Notably, the increase in M2 macrophage population at the acute stage of $\mathrm{SCI}$ is in agreement with our previous cytokine study in SCI where we observed elevated levels of M2 markers such as arginase- 1 and IL-10 under Nrg-1 therapy [13]. M2 macrophages are shown to promote oligodendrocyte differentiation, survival, and remyelination [62] and are associated with overall tissue preservation and improved recovery of function following SCI [63]. In the chronically injured spinal cord tissue, however, it was intriguing that Nrg-1 treatment more prominently promoted the population of M1 macrophages with a concurrent increase in IL-10 expressing M2 subpopulation. Further studies are required to fully elucidate the underlying mechanisms of Nrg-1 in macrophage regulation.

We show that Nrg-1 treatment provided a more balanced chemokine profile after SCI. Nrg-1 elevated the expression level of CCL11 in chronic SCI. CCL11 is produced by microphages/microglia, astrocytes, and pericytes [64-66]. Similar to IL-10, CCL11 is known to have anti-inflammatory function and protects neural tissue during inflammatory process [39]. CCL11 also increases migration and proliferation of neural precursor cells following cerebral ischemic injury [43], which is a prerequisite for endogenous cell replacement. We additionally showed that Nrg-1 attenuated the expression of CXCL1 in acute SCI. This chemokine is produced by mast cells, macrophages, and astrocytes and contributes to neutrophil recruitment and exacerbate neuroinflammation following CNS injury [45]. Interestingly, CXCL1 is known to be regulated by IL-6 [67], an inflammatory cytokine produced by macrophages, microglia, and astrocytes in SCI $[68,69]$. Thus, these data suggest a correlation between downregulation of CXCL1 and reduction in IL- 6 expression by Nrg-1 in our acute SCI studies. Notably, inhibition of IL-6 signaling is associated with reduced glial scarring and improves functional recovery [70] and neuropathic pain following SCI [25]. Our chemokine profiling also showed the potential of Nrg-1 in attenuating the expression of CXCL2 and CXCL10. CXCL2 is known to induce neuronal injury in motoneuron cultures [71] supportive of a neuroprotective role for Nrg-1 in CNS injury. CXCL10, also known as interferon-gamma-induced protein 10 , is a proinflammatory chemokine produced by macrophages, fibroblasts, astrocytes, and endothelial cells upon IFN- $\gamma$ stimulation [72]. Neutralization of CXCL10 has been associated with decreased secondary tissue degeneration and improvement of functional recovery in murine SCI [35]. Taken together, our chemokine analysis indicates that while Nrg-1 promotes the overall recruitment of macrophages into the injured spinal cord, it activates a phenotype in macrophages that can facilitate repair processes following SCI.
A novel finding in our study is the modulatory effect of Nrg-1 on T cells after SCI. We have provided the first evidence that Nrg-1 treatment remarkably enhances a $\mathrm{T}_{\text {reg }}$ response in acute, subacute, and chronic SCI. Most interestingly, Nrg-1 exerts its beneficial effects systemically by increasing the population of circulating $\mathrm{T}_{\text {reg }}$ cells in the bloodstream in chronic SCI. $\mathrm{T}_{\text {reg }}$ cells play pivotal roles in regulating an adaptive immune response and preventing autoimmune reactions [73]. Ablation of $T_{\text {reg }}$ cells elicits an intensive $T_{\text {eff }}$ response that induces neuronal death following CNS injury [54]. In our study, we showed the ability of systemic Nrg-1 treatment to suppress the population of pro-inflammatory $\mathrm{CD}^{+} \mathrm{CD} 4^{+} \mathrm{IFN}-\gamma^{+}$effector $\mathrm{T}$ cells and reduce IFN- $\gamma^{+}$within the injured spinal cord tissue at subacute SCI. Of note, IFN- $\gamma$ is primarily produced by lymphocytes including effector Th1 cells and promotes classic macrophage activation [29] and neuropathic pain [24]. Importantly, IFN- $\gamma$ is implicated in inducing white matter degeneration and necrosis following cerebral ischemia/reperfusion injury and increasing the susceptibility of neurons to apoptosis $[74,75]$. SCI studies have shown that IFN- $\gamma$ directs its degenerative effects by promoting proliferation of cytotoxic $\mathrm{T}$ cells $[8,76]$. Indeed, reduction in IFN- $\gamma$ expression in subacute SCI under Nrg-1 treatment in this study provides an underlying mechanism by which Nrg-1 ameliorated white matter degeneration in the injured spinal cord in our previous studies $[11,13]$. Nrg-1 also induced a reduction in the expression of CCL5 (RANTES), a pro-inflammatory chemokine produced by astrocytes as well as $\mathrm{T}$ cells upon macrophage stimulation $[68,77]$. This observation correlates well with the increased M2 macrophages and decreased population of effector $\mathrm{T}$ cells that we observed in our immunophenotypic studies. Increase in CCL5 is implicated in microvascular dysfunction following CNS injury [42]. Altogether, our observations indicate that Nrg-1 is a positive modulator of $\mathrm{T}$ cell response after SCI. Therefore, increasing the deficient levels of Nrg-1 after injury has therapeutic value to augment a $\mathrm{T}$ regulatory immune response during the repair processes following SCI.

$\mathrm{SCI}$ also elicits a $\mathrm{B}$ cell response in the spleen and bone marrow characterized by increased B cell number and elevated serum immunoglobulin levels [4]. Our findings provide new evidence that Nrg-1 promotes recruitment and regulatory phenotype of B cells in the injured spinal cord with a more pronounced effect at the chronic stage of injury. Similar to T cells, the increase in $B$ cell response mainly represented a rise in the $B_{\text {reg }}$ population in response to $\mathrm{Nrg}-1$ treatment. Interestingly, in contrast to the spinal cord, the number of $\mathrm{B}$ cells was initially dropped in the blood after SCI which was independent of Nrg-1 treatment. This observation 
is consistent with previous reports that showed SCI induces an initial cessation of $\mathrm{B}$ cell production in the bone marrow [23]. There is also evidence that $\mathrm{B}$ cells undergo extensive apoptosis following SCI. B cells are the integral component of the adaptive humoral immune response and capable of producing a wide variety of cytokines [10]. Following SCI, B cells produce autoantibodies against spinal cord tissue that can aggravate the secondary injury processes through complement and $\mathrm{Fc}$ receptor (FCR)-dependent mechanisms [21]. Similar to other immune cells, phenotype and function of B cells can be regulated by the signaling molecules and cytokines available in their microenvironment [10]. $\mathrm{B}_{\text {reg }}$ cells support repair processes as they can suppress activation of helper $\mathrm{T}$ cell and their production of TNF$\alpha$ and IFN- $\gamma$ as well as TNF- $\alpha$ production by monocytes [78-80]. Importantly, $B_{\text {reg }}$ cells play essential roles in the formation and maintenance of $\mathrm{T}_{\text {reg }}$ cell population [81]. Moreover, $B_{\text {reg }}$ cell-mediated IL-10 production has been shown to limit tissue damage and improve recovery of function in a murine model of brain ischemia [22]. For the first time, we uncovered that Nrg-1 attenuates antibody deposition in the injured spinal cord. Our analysis of IgG and IgM showed that Nrg-1 was mainly effective subacutely. It is plausible that Nrg-1mediated reduction in the spinal cord levels of IgM and IgG in subacute SCI reflects an indirect role for Nrglin modulation of vascular permeability. We have previously shown that Nrg-1 treatment attenuates the activity of matrix metalloproteinase (MMP)-9 in the injured spinal cord tissue [13]. MMP-9 is involved in the disruption of blood-spinal barrier [3]. Moreover, IL-6 can increase antibody production by B cells [82]. Thus, the Nrg-1-induced decline in IL-6 expression in our acute SCI studies can be another underlying cause for the reduced antibody deposition in the injured spinal cord at the subacute stage without alteration in B cell number. Our immunohistochemical analysis showed an increasing trend in IgG deposition in the spinal cord tissue with Nrg-1 treatment at chronic (42-day) timepoint. This observation may reflect the modulatory effect of Nrg-1 on B cells that reside chronically in the spinal cord tissue. Our analysis of spinal cord B cells showed a close correlation between increased $B_{\text {reg }}$ population in Nrg-1-treated animals and a trend towards higher production of IgG within the chronically injured spinal cord. This is in line with other studies that have attributed IgG production to $B_{\text {reg }}$ cells [83]. Interestingly, IgG deposition by $\mathrm{B}_{\text {reg }}$ cells has been associated with beneficial immunomodulatory roles that include neutralizing harmful antigens from the microenvironment, inhibiting macrophages and dendritic cell activation, and enhancing the clearance of apoptotic bodies that contain self-antigens [83]. Moreover, studies by Nguyen and colleagues have also shown a positive role for IgG in recovery from SCI [84]. These studies revealed that systemic IgG administration increased IgG deposition in the injured spinal cord, which was associated with improved neural tissue preservation and functional recovery in a rat model of cervical SCI [84]. This evidence suggests that increased level of IgG may exert beneficial effects in SCI. Of note, our previous studies identified that Nrg-1 treatment improves tissue preservation in chronic SCI [13] that could be attributed, at least in part, to the increase in $\mathrm{B}_{\text {reg }}$ cells and IgG production.

\section{Conclusions}

The present study, for the first time, implicates Nrg-1 as a positive regulator of neuroinflammation after SCI. We demonstrate that systemic bioavailability of Nrg- 1 induces a pro-regenerative immune response in leukocytes that fosters a supportive environment for repair and regeneration in the injured spinal cord. Identification of a multifaceted immunoregulatory role for Nrg-1 establishes a novel therapeutic target for treating traumatic SCI and other CNS neuroinflammatory conditions.

\section{Additional file}

\begin{abstract}
Additional file 1: Figure S1. Flow cytometric verification of antibody specificity on injured and uninjured spinal cord tissue. (A-C) Spinal cord immune cells were gated for the detection of macrophages and their pro-inflammatory $\left(\mathrm{M} 1, \mathrm{CD} 45^{+} \mathrm{CD} 68^{+} \mathrm{CD} 86^{+}\right)$and pro-regenerative $\left(\mathrm{M} 2, \mathrm{CD} 45^{+} \mathrm{CD}_{6}{ }^{+} \mathrm{CD} 163^{+}\right)$subpopulations. Our verification showed a negligible number of macrophages in the injured isotype control and no positively stained cells in the unstained control compared to the stained injured group confirming the specificity of antibodies used in our macrophage panel. Figure S2. Flow cytometric verification of antibody specificity for T cell detection. (A-C) Isolated spinal cord immune cells were stained and gated for the detection of helper $T$ cells and their effector $\left(T_{\text {eff, }} C D 3^{+} C D 4^{+} I F N \gamma^{+}\right)$and regulatory $\left(T_{\text {reg, }}, C D 3^{+} C D 4^{+} \mathrm{IL}-10^{+}\right)$ subpopulations. A negligible number of $T$ cells were detected in the injured isotype and the unstained control compared to the stained injured group confirming the specificity of antibodies used in our $T$ cell panel. Figure S3. Specificity of the antibodies used for B cell detection was verified as shown above. (A-C) Isolated spinal cord immune cells were stained and gated for the detection of B cells and their ( $B_{\text {reg, }}$ CD45RA ${ }^{+} I L-10^{+}$) subpopulation. Our analysis showed a negligible number of B cells in the injured isotype control and no B cells in the unstained control group compared to stained injured group confirming the specificity of our B cell antibody panel. Figure S4. Immunohistochemical staining of the spinal cord sections at $1 \mathrm{~mm}$ caudal to the injury epicenter was performed to verify the tissue distribution of (A) macrophages/microglia $\left(\mathrm{Iba}-1^{+}\right),(\mathrm{B}) \mathrm{T}$ cells $\left(\mathrm{CD}^{+}\right)$, and (C) B cells $\left(\mathrm{CD} 45 \mathrm{RA} \mathrm{A}^{+}\right)$at 2 weeks post-injury. Dashed lines show the contour of the spinal cord section. Immune cells were mostly found within the SCI lesion. Magnified pictures and white arrows show the presence of (A) $\mathrm{Iba}-1^{+} / \mathrm{IL}-10^{+}$macrophages/ microglia, (B) $\mathrm{CD}^{+} / \mathrm{IL}-10^{+} \mathrm{T}$ cells, and (C) CD45RA ${ }^{+} / \mathrm{L}-10^{+} \mathrm{B}$ cells, confirming the presence of these cells in the injured spinal cord tissue. (PDF $4416 \mathrm{~kb}$ )
\end{abstract}

\section{Abbreviations}

aCSF: Artificial cerebrospinal fluid; ANOVA: Analysis of variance; $B_{\text {reg: }}$ Regulatory B cells; CCL: C-C motif ligands; CNS: Central nervous system; CSPGs: Chondroitin sulfate proteoglycans; CXCL: C-X-C motif ligands; CXCR: CXC chemokine receptor; DMEM: Dulbecco's modified Eagle's media; FoxP3: Forkhead box P3; HBSS: Hank's Balanced Salt Solution; IL-10: Interleukin- 
10; IL-13: Interleukin-1 beta; IL-6: Interleukin-6; MMP: Matrix metalloproteinase; NFkBIZ: NFkB inhibitor zeta; NF-kB: Nuclear factor kappa B; NO: Nitric oxide; Nrg-1: Neuregulin-1; PFA: Paraformaldehyde; RBC: Red blood cell; rhNrg1: Recombinant human Nrg-1; SCl: Spinal cord injury; SD: Sprague-Dawley; SEM: Standard error of the mean; $T_{\text {eff. }}$ Effector T cells; TNF- : Tumor necrosis factor-alpha; $T_{\text {reg: }}$ Regulatory $T$ cells

\section{Acknowledgements}

The authors would like to thank Dr. Hesam Movassagh for providing technical training.

\section{Funding}

This work was supported by operating grants awarded to SK-A from the Canadian Institutes of Health Research (CIHR, Grant No: MOP 133721), the Canadian Paraplegic Association of Manitoba, and the Manitoba Paraplegic Foundation. Salary support for AA was provided by CHRIM, Research Manitoba and GETS program of the $U$ of M. HK was supported by a post-doctoral fellowship from the Research Manitoba and the Rick Hansen Institute.

\section{Availability of data and materials}

The datasets generated during and/or analyzed during the current study are available from the corresponding author on reasonable request.

\section{Authors' contributions}

AA, SK-A, and ASG conceived and designed the research. AA, KTS, and HK performed the research and analyzed the data. AA and SK-A wrote the paper. All authors read and approved the final manuscript.

\section{Ethics approval}

All experimental protocols in this study involving animals were approved by the Animal Care Committee of University of Manitoba in accordance with the guidelines and policies established by the Canadian Council on Animal Care, protocol number: 15030 (AC11067).

\section{Consent for publication}

Not applicable.

\section{Competing interests}

The authors declare that they have no competing interests.

\section{Publisher's Note}

Springer Nature remains neutral with regard to jurisdictional claims in published maps and institutional affiliations.

\section{Author details}

${ }^{1}$ Regenerative Medicine Program, Department of Physiology and Pathophysiology, Faculty of Medicine, Spinal Cord Research Centre, University of Manitoba, 629-Basic Medical Sciences Building, 745 Bannatyne Avenue, Winnipeg, Manitoba R3E 0J9, Canada. ²Department of Immunology, University of Manitoba, Winnipeg, Manitoba, Canada.

\section{Received: 7 November 2017 Accepted: 7 February 2018}

\section{Published online: 21 February 2018}

\section{References}

1. Trivedi A, Olivas AD, Noble-Haeusslein LJ. Inflammation and spinal cord injury: infiltrating leukocytes as determinants of injury and repair processes. Clin Neurosci Res. 2006:6:283-92.

2. Fitch MT, Doller C, Combs CK, Landreth GE, Silver J. Cellular and molecular mechanisms of glial scarring and progressive cavitation: in vivo and in vitro analysis of inflammation-induced secondary injury after CNS trauma. J Neurosci. 1999;19:8182-98.

3. Noble LJ, Donovan F, Igarashi T, Goussev S, Werb Z. Matrix metalloproteinases limit functional recovery after spinal cord injury by modulation of early vascular events. J Neurosci. 2002;22:7526-35.

4. Ankeny DP, Lucin KM, Sanders VM, McGaughy VM, Popovich PG. Spinal cord injury triggers systemic autoimmunity: evidence for chronic B lymphocyte activation and lupus-like autoantibody synthesis. J Neurochem. 2006;99:1073-87.
5. Zhao WXW, Le W, Beers DR, He Y, Henkel JS, Simpson EP, Yen AA, Xiao Q, Appel $\mathrm{SH}$. Activated microglia initiate motor neuron injury by a nitric oxide and glutamate-mediated mechanism. J Neuropathol Exp Neurol. 2004;63:964-77.

6. Hoffman W, Lakkis FG, Chalasani G. B cells, antibodies, and more. Clin J Am Soc Nephrol. 2016;11:137-54.

7. Kil K, Zang YC, Yang D, Markowski J, Fuoco GS, Vendetti GC, Rivera VM, Zhang JZ. T cell responses to myelin basic protein in patients with spinal cord injury and multiple sclerosis. J Neuroimmunol. 1999;98:201-7.

8. Sun D, Whitaker JN, Huang Z, Liu D, Coleclough C, Wekerle H, Raine CS. Myelin antigen-specific CD8+ T cells are encephalitogenic and produce severe disease in C57BL/6 mice. J Immunol. 2001;166:7579-87.

9. Lodge PA, Sriram S. Regulation of microglial activation by TGF-beta, IL-10, and CSF-1.J Leukoc Biol. 1996:60:502-8.

10. Vazquez MI, Catalan-Dibene J, Zlotnik A. B cells responses and cytokine production are regulated by their immune microenvironment. Cytokine. 2015;74:318-26.

11. Gauthier M-K, Kosciuczyk K, Tapley L, Karimi-Abdolrezaee S. Dysregulation of the neuregulin-1-ErbB network modulates endogenous oligodendrocyte differentiation and preservation after spinal cord injury. Eur J Neurosci. 2013; 38:2693-715.

12. Bartus K, Galino J, James ND, Hernandez-Miranda LR, Dawes JM, Fricker FR, Garratt AN, McMahon SB, Ramer MS, Birchmeier C, et al. Neuregulin-1 controls an endogenous repair mechanism after spinal cord injury. Brain. 2016;139:1394-1416.

13. Alizadeh A, Dyck SM, Kataria H, Shahriary GM, Nguyen DH, Santhosh KT, KarimiAbdolrezaee S. Neuregulin-1 positively modulates glial response and improves neurological recovery following traumatic spinal cord injury. Glia. 2017;65:1152-75.

14. Simmons LJ, Surles-Zeigler MC, Li Y, Ford GD, Newman GD, Ford BD. Regulation of inflammatory responses by neuregulin-1 in brain ischemia and microglial cells in vitro involves the NF-kappa B pathway. J Neuroinflammation. 2016:13:237.

15. Guo WP, Wang J, Li RX, Peng YW. Neuroprotective effects of neuregulin-1 in rat models of focal cerebral ischemia. Brain Res. 2006;1087:180-5.

16. Nguyen HX, Beck KD, Anderson AJ. Quantitative Assessment of Immune Cells in the Injured Spinal Cord Tissue by Flow Cytometry: a Novel Use for a Cell Purification Method. Journal of Visualized Experiments : JoVE. 2011;(50): 2698. https://doi.org/10.3791/2698.

17. Karimi-Abdolrezaee S, Eftekharpour E, Wang J, Schut D, Fehlings MG. Synergistic effects of transplanted adult neural stem/progenitor cells, chondroitinase, and growth factors promote functional repair and plasticity of the chronically injured spinal cord. J Neurosci. 2010;30:1657-76.

18. Shechter R, London A, Varol C, Raposo C, Cusimano M, Yovel G, et al. Infiltrating Blood-Derived Macrophages Are Vital Cells Playing an Antiinflammatory Role in Recovery from Spinal Cord Injury in Mice. PLoS Med. 2009;6(7):e1000113. https://doi.org/10.1371/journal.pmed.1000113.

19. Zhang N, Yin Y, Xu SJ, Wu YP, Chen WS. Inflammation \& apoptosis in spinal cord injury. Indian J Med Res. 2012;135:287-96.

20. Jones TB. Lymphocytes and autoimmunity after spinal cord injury. Exp Neurol. 2014;258:78-90.

21. Ankeny DP, Guan Z, Popovich PG. B cells produce pathogenic antibodies and impair recovery after spinal cord injury in mice. J Clin Invest. 2009;119:2990-9.

22. Ren X, Akiyoshi K, Dziennis S, Vandenbark AA, Herson PS, Hurn PD, Offner H. Regulatory B cells limit CNS inflammation and neurologic deficits in murine experimental stroke. J Neurosci. 2011:31:8556-63.

23. Oropallo MA, Goenka R, Cancro MP. Spinal cord injury impacts B cell production, homeostasis, and activation. Semin Immunol. 2014:26:421-7.

24. Tsuda M, Masuda T, Kitano J, Shimoyama H, Tozaki-Saitoh H, Inoue K. IFNgamma receptor signaling mediates spinal microglia activation driving neuropathic pain. Proc Natl Acad Sci U S A. 2009;106:8032-7.

25. Guptarak J, Wanchoo S, Durham-Lee J, Wu Y, Zivadinovic D, PaulucciHolthauzen A, Nesic O. Inhibition of IL-6 signaling: a novel therapeutic approach to treating spinal cord injury pain. Pain. 2013;154:1115-28.

26. Yaguchi M, Ohta S, Toyama Y, Kawakami Y, Toda M. Functional recovery after spinal cord injury in mice through activation of microglia and dendritic cells after IL-12 administration. J Neurosci Res. 2008:86:1972-80.

27. Brewer KL, Bethea JR, Yezierski RP. Neuroprotective effects of interleukin-10 following excitotoxic spinal cord injury. Exp Neurol. 1999;159:484-93.

28. Schroder K, Hertzog PJ, Ravasi T, Hume DA. Interferon-gamma: an overview of signals, mechanisms and functions. J Leukoc Biol. 2004;75:163-89.

29. Su X, Yu Y, Zhong Y, Giannopoulou EG, Hu X, Liu H, Cross JR, Ratsch G, Rice CM, Ivashkiv LB. Interferon-gamma regulates cellular metabolism and mRNA translation to potentiate macrophage activation. Nat Immunol. 2015;16:838-49. 
30. Kaplin Al, Deshpande DM, Scott E, Krishnan C, Carmen JS, Shats I, Martinez T, Drummond J, Dike S, Pletnikov M, et al. IL-6 induces regionally selective spinal cord injury in patients with the neuroinflammatory disorder transverse myelitis. J Clin Invest. 2005;115:2731-41.

31. Pagenstecher A, Lassmann S, Carson MJ, Kincaid CL, Stalder AK, Campbell IL. Astrocyte-targeted expression of IL-12 induces active cellular immune responses in the central nervous system and modulates experimental allergic encephalomyelitis. J Immunol. 2000;164:4481-92.

32. Gunther J, Esch K, Poschadel N, Petzl W, Zerbe H, Mitterhuemer S, Blum H, Seyfert HM. Comparative kinetics of Escherichia coli- and Staphylococcus aureus-specific activation of key immune pathways in mammary epithelial cells demonstrates that S. aureus elicits a delayed response dominated by interleukin-6 (IL-6) but not by IL-1A or tumor necrosis factor alpha. Infect Immun. 2011;79:695-707.

33. Seshadri S, Kannan Y, Mitra S, Parker-Barnes J, Wewers MD. MAlL regulates human monocyte IL-6 production. J Immunol. 2009;183:5358-68.

34. Marsh DR, Flemming JM. Inhibition of CXCR1 and CXCR2 chemokine receptors attenuates acute inflammation, preserves gray matter and diminishes autonomic dysreflexia after spinal cord injury. Spinal Cord. 2011;49:337-44.

35. Gonzalez R, Hickey MJ, Espinosa JM, Nistor G, Lane TE, Keirstead HS. Therapeutic neutralization of CXCL10 decreases secondary degeneration and functional deficit after spinal cord injury in mice. Regen Med. 2007;2:771-83.

36. Zhang ZJ, Cao DL, Zhang X, Ji RR, Gao YJ. Chemokine contribution to neuropathic pain: respective induction of CXCL1 and CXCR2 in spinal cord astrocytes and neurons. Pain. 2013;154:2185-97.

37. Hassanshahi G, Amin M, Shunmugavel A, Vazirinejad R, Vakilian A, Sanji M, Shamsizadeh A, RafatPanah H, Poor NM, Moosavi SR, Taheri S. Temporal expression profile of CXC chemokines in serum of patients with spinal cord injury. Neurochem Int. 2013;63:363-7.

38. Lin MS, Sun YY, Chiu WT, Hung CC, Chang CY, Shie FS, Tsai SH, Lin JW, Hung KS, Lee $\mathrm{YH}$. Curcumin attenuates the expression and secretion of RANTES after spinal cord injury in vivo and lipopolysaccharide-induced astrocyte reactivation in vitro. J Neurotrauma. 2011;28:1259-69.

39. Adzemovic MZ, Ockinger J, Zeitelhofer M, Hochmeister S, Beyeen AD, Paulson A, Gillett A, Thessen Hedreul M, Covacu R, Lassmann H, et al. Expression of $\mathrm{CCl} 11$ associates with immune response modulation and protection against neuroinflammation in rats. PLoS One. 2012;7:e39794.

40. Hiura TS, Kempiak SJ, Nel AE. Activation of the human RANTES gene promoter in a macrophage cell line by lipopolysaccharide is dependent on stress-activated protein kinases and the IkappaB kinase cascade: implications for exacerbation of allergic inflammation by environmental pollutants. Clin Immunol. 1999;90:287-301.

41. Kim MO, Suh HS, Brosnan CF, Lee SC. Regulation of RANTES/CCL5 expression in human astrocytes by interleukin-1 and interferon-beta. J Neurochem. 2004;90:297-308.

42. Terao S, Yilmaz G, Stokes KY, Russell J, Ishikawa M, Kawase T, Granger DN. Blood cell-derived RANTES mediates cerebral microvascular dysfunction, inflammation, and tissue injury after focal ischemia-reperfusion. Stroke. 2008;39:2560-70.

43. Wang F, Baba N, Shen Y, Yamashita T, Tsuru E, Tsuda M, Maeda N, Sagara Y. CCL11 promotes migration and proliferation of mouse neural progenitor cells. Stem Cell Res Ther. 2017;8:26.

44. Tyagi P, Kadekawa K, Kashyap M, Pore S, Yoshimura N. Spontaneous recovery of reflex voiding following spinal cord injury mediated by antiinflammatory and neuroprotective factors. Urology. 2016;88:57-65.

45. De Filippo K, Dudeck A, Hasenberg M, Nye E, van Rooijen N, Hartmann K, Gunzer M, Roers A, Hogg N. Mast cell and macrophage chemokines CXCL1/ CXCL2 control the early stage of neutrophil recruitment during tissue inflammation. Blood. 2013;121:4930-7.

46. Kastin AJ, Akerstrom V, Pan W. Neuregulin-1-beta1 enters brain and spinal cord by receptor-mediated transport. J Neurochem. 2004;88:965-70.

47. Xu Z, Croslan DR, Harris AE, Ford GD, Ford BD. Extended therapeutic window and functional recovery after intraarterial administration of neuregulin-1 after focal ischemic stroke. J Cereb Blood Flow Metab. 2006;26:527-35.

48. Brinkmann BG, Agarwal A, Sereda MW, Garratt AN, Muller T, Wende H, Stassart RM, Nawaz S, Humml C, Velanac V, et al. Neuregulin-1/ErbB signaling serves distinct functions in myelination of the peripheral and central nervous system. Neuron. 2008:59:581-95.

49. Hancock ML, Nowakowski DW, Role LW, Talmage DA, Flanagan JG. Type III neuregulin 1 regulates pathfinding of sensory axons in the developing spinal cord and periphery. Development. 2011;138:4887-98.

50. Vartanian T, Fischbach $G$, Miller R. Failure of spinal cord oligodendrocyte development in mice lacking neuregulin. Proc Natl Acad Sci U S A. 1999;96:731-5.
51. Dyck SM, Karimi-Abdolrezaee S. Chondroitin sulfate proteoglycans: key modulators in the developing and pathologic central nervous system. Exp Neurol. 2015;269:169-87.

52. Mencel M, Nash $M$, Jacobson C. Neuregulin upregulates microglial alpha7 nicotinic acetylcholine receptor expression in immortalized cell lines: implications for regulating neuroinflammation. PLoS One. 2013;8:e70338.

53. Puntambekar SS, Hinton DR, Yin X, Savarin C, Bergmann CC, Trapp BD, Stohlman SA. Interleukin-10 is a critical regulator of white matter lesion containment following viral induced demyelination. Glia. 2015;63:2160-2120.

54. Walsh JT, Zheng J, Smirnov I, Lorenz U, Tung K, Kipnis J. Regulatory T cells in central nervous system injury: a double-edged sword. J Immunol. 2014; 193:5013-22.

55. Das A, Ellis G, Pallant C, Lopes AR, Khanna P, Peppa D, Chen A, Blair P, Dusheiko $G$, Gill U, et al. IL-10-producing regulatory $B$ cells in the pathogenesis of chronic hepatitis B virus infection. J Immunol. 2012;189:3925-35.

56. Chung EY, Liu J, Homma Y, Zhang Y, Brendolan A, Saggese M, Han J, Silverstein $\mathrm{R}$, Selleri L, Ma X. Interleukin-10 expression in macrophages during phagocytosis of apoptotic cells is mediated by homeodomain proteins Pbx1 and Prep-1. Immunity. 2007;27:952-64.

57. Cannella B, Pitt D, Marchionni M, Raine CS. Neuregulin and erbB receptor expression in normal and diseased human white matter. J Neuroimmunol. 1999;100:233-42.

58. Ryzhov S, Matafonov A, Galindo CL, Zhang Q, Tran TL, Lenihan DJ, Lenneman CG, Feoktistov I, Sawyer DB. ERBB signaling attenuates proinflammatory activation of nonclassical monocytes. Am J Physiol Heart Circ Physiol. 2017;312:H907-18.

59. Tynyakov-Samra E, Auriel E, Levy-Amir Y, Karni A. Reduced ErbB4 expression in immune cells of patients with relapsing remitting multiple sclerosis. Mult Scler Int. 2011;2011:561262

60. Calvo M, Zhu N, Tsantoulas C, Ma Z, Grist J, Loeb JA, Bennett DL. Neuregulin-ErbB signaling promotes microglial proliferation and chemotaxis contributing to microgliosis and pain after peripheral nerve injury. $J$ Neurosci. 2010;30:5437-50.

61. Calvo M, Zhu N, Grist J, Ma Z, Loeb JA, Bennett DL. Following nerve injury neuregulin-1 drives microglial proliferation and neuropathic pain via the MEK/ERK pathway. Glia. 2011:59:554-68.

62. Miron VE, Boyd A, Zhao JW, Yuen TJ, Ruckh JM, Shadrach JL, van Wijngaarden P, Wagers AJ, Williams A, Franklin RJ, Ffrench-Constant C. M2 microglia and macrophages drive oligodendrocyte differentiation during CNS remyelination. Nat Neurosci. 2013;16:1211-8.

63. Shin T, Ahn M, Moon C, Kim S, Sim KB. Alternatively activated macrophages in spinal cord injury and remission: another mechanism for repair? Mol Neurobiol. 2013;47:1011-9.

64. Kovac A, Erickson MA, Banks WA. Brain microvascular pericytes are immunoactive in culture: cytokine, chemokine, nitric oxide, and LRP-1 expression in response to lipopolysaccharide. J Neuroinflammation. 2011;8:139.

65. Parajuli B, Horiuchi H, Mizuno T, Takeuchi H, Suzumura A. CCL11 enhances excitotoxic neuronal death by producing reactive oxygen species in microglia. Glia. 2015;63:2274-84.

66. Yang LP, Zhu XA, Tso MO. Minocycline and sulforaphane inhibited lipopolysaccharide-mediated retinal microglial activation. Mol Vis. 2007;13:1083-93.

67. Roy M, Richard JF, Dumas A, Vallieres L. CXCL1 can be regulated by IL- 6 and promotes granulocyte adhesion to brain capillaries during bacterial toxin exposure and encephalomyelitis. J Neuroinflammation. 2012;9:18.

68. Choi SS, Lee HJ, Lim I, Satoh J, Kim SU. Human astrocytes: secretome profiles of cytokines and chemokines. PLoS One. 2014;9:e92325.

69. Hunter CA, Jones SA. IL-6 as a keystone cytokine in health and disease. Nat Immunol. 2015;16:448-57.

70. Nakamura M, Okada S, Toyama Y, Okano H. Role of IL-6 in spinal cord injury in a mouse model. Clin Rev Allergy Immunol. 2005;28:197-204.

71. De Paola M, Buanne P, Biordi L, Bertini R, Ghezzi P, Mennini T. Chemokine MIP-2/CXCL2, acting on CXCR2, induces motor neuron death in primary cultures. Neuroimmunomodulation. 2007:14:310-6.

72. Luster AD, Unkeless JC, Ravetch JV. Gamma-interferon transcriptionally regulates an early-response gene containing homology to platelet proteins. Nature. 1985;315:672-6.

73. Zhou R, Horai R, Silver PB, Mattapallil MJ, Zarate-Blades CR, Chong WP, Chen J, Rigden RC, Villasmil R, Caspi RR. The living eye "disarms" uncommitted autoreactive $T$ cells by converting them to Foxp3(+) regulatory cells following local antigen recognition. J Immunol. 2012;188:1742-50. 
74. Bate C, Kempster S, Last V, Williams A. Interferon-gamma increases neuronal death in response to amyloid-beta1-42. J Neuroinflammation. 2006;3:7.

75. Yilmaz G, Arumugam TV, Stokes KY, Granger DN. Role of T lymphocytes and interferon-gamma in ischemic stroke. Circulation. 2006;113:2105-12.

76. Deb C, Lafrance-Corey RG, Schmalstieg WF, Sauer BM, Wang H, German CL, Windebank AJ, Rodriguez M, Howe CL. CD8+ T cells cause disability and axon loss in a mouse model of multiple sclerosis. PLoS One. 2010;5:e12478.

77. Swanson BJ, Murakami M, Mitchell TC, Kappler J, Marrack P. RANTES production by memory phenotype T cells is controlled by a posttranscriptional, TCR-dependent process. Immunity. 2002;17:605-15.

78. Bouaziz JD, Calbo S, Maho-Vaillant M, Saussine A, Bagot M, Bensussan A, Musette P. IL-10 produced by activated human B cells regulates CD4(+) Tcell activation in vitro. Eur J Immunol. 2010;40:2686-91.

79. Blair PA, Norena LY, Flores-Borja F, Rawlings DJ, Isenberg DA, Ehrenstein MR, Mauri C. CD19(+)CD24(hi)CD38(hi) B cells exhibit regulatory capacity in healthy individuals but are functionally impaired in systemic lupus erythematosus patients. Immunity. 2010;32:129-40.

80. Iwata Y, Matsushita T, Horikawa M, Dilillo DJ, Yanaba K, Venturi GM, Szabolcs PM, Bernstein SH, Magro CM, Williams AD, et al. Characterization of a rare IL-10-competent B-cell subset in humans that parallels mouse regulatory B10 cells. Blood. 2011;117:530-41.

81. Pennati A, Ng S, Wu Y, Murphy JR, Deng J, Rangaraju S, Asress S, Blanchfield JL, Evavold B, Galipeau J. Regulatory B cells induce formation of IL-10 expressing T cells in mice with autoimmune neuroinflammation. J Neurosci. 2016;

82. Maeda K, Mehta H, Drevets DA, Coggeshall KM. IL-6 increases B-cell IgG production in a feed-forward proinflammatory mechanism to skew hematopoiesis and elevate myeloid production. Blood. 2010;115:4699-706.

83. Mizoguchi A, Bhan AK. A case for regulatory B cells. J Immunol. 2006;176:705-10.

84. Nguyen DH, Cho N, Satkunendrarajah K, Austin JW, Wang J, Fehlings MG. Immunoglobulin $\mathrm{G}(\mathrm{lgG})$ attenuates neuroinflammation and improves neurobehavioral recovery after cervical spinal cord injury. J Neuroinflammation. 2012;9:224.

\section{Submit your next manuscript to BioMed Central and we will help you at every step:}

- We accept pre-submission inquiries

- Our selector tool helps you to find the most relevant journal

- We provide round the clock customer support

- Convenient online submission

- Thorough peer review

- Inclusion in PubMed and all major indexing services

- Maximum visibility for your research

Submit your manuscript at www.biomedcentral.com/submit 